\title{
Biohydrogen production and bioprocess enhancement: A review
}

\author{
Ackmez Mudhoo $^{\mathrm{a}, *}$, T. Forster-Carneiro ${ }^{\mathrm{b}}$ and Antoni Sánchez ${ }^{\mathrm{c}}$ \\ ${ }^{a}$ Department of Chemical and Environmental Engineering, Faculty of Engineering, \\ University of Mauritius, Réduit, Mauritius \\ ${ }^{\mathrm{b}}$ Department Chemical Engineering, Food Technology and Environmental \\ Technologies, Faculty of Sea Sciences and Environmental Sciences, University of \\ Cadiz, Campus Rio San Pedro s/n, 11510-Puerto Real, Cádiz, Spain \\ ${ }^{c}$ Departament d'Enginyeria Química, Escola Tècnica Superior d'Enginyeria, Universitat \\ Autònoma de Barcelona, 08193-Bellaterra, Barcelona, Spain
}

* Corresponding Author: Ackmez Mudhoo (ackmezchem@yahoo.co.uk).

Tel: (+230) 4037772; (+230) 7757994; Fax: (+230) 4657144.

Postal Address of Corresponding Author: 4, Rajiv Gandhi Street, Maurel Road, Rivière du Rempart, Mauritius.

\begin{abstract}
This manuscript provides a review of the actual state and the most recent advances as well as current trends and future prospects in biological production of hydrogen (Biohydrogen). Biohydrogen has attracted worldwide attention and enjoys much promise as a green fuel, an important component for the energy balance of a global economy. Hydrogen from both fossil and renewable biomass resources is a source sustainable source of energy not limited and of different applications. The most commonly used technologies of biohydrogen production including direct biophotolysis, indirect biophotolysis, photo-fermentations, and dark-fermentation, conventional or "modern" techniques are examined in detail. It identifies the key limitations (chemical reactions and reactor design) to an increased biohydrogen production and suggests different substrates of renewable sources. Thereafter, discusses the several physical pretreatment, design reactor, biochemical and genetic manipulations techniques that are being developed to enhance the overall rates and yields.
\end{abstract}

\section{Keywords}

Hydrogen; Biohydrogen production; Biofuel; Biomass resources; Green chemistry; Pretreatment; Reactor configurations; Bacterial Strains; Genetic manipulation

Pre-print of: Modhoo, A.; Forster-Carneiro, T. and Sánchez, A. "Biohydrogen production and bioprocess enhancement : a review" in Critical reviews in Biotechnology (Ed. Taylor and Francis), vol. 31, issue 3 (Sep. 2011), p. 250-263. The final version is available at DOI 10.3109/07388551.2010.525497

\footnotetext{
${ }^{1}$ Co-Authors: Tânia Forster Carneiro (tania.forster@uca.es) Tel: (+34) 975123723; Antoni Sánchez (antoni.sanchez@uab.cat) Tel: (+34) 935811019, Fax: (+34) 935812013
} 


\section{Contents}

1. Introduction

1.1 The biohydrogen alternative

1.2. Green technology and biohydrogen production.....

2. Biohydrogen production methods

2.1. Biophotolysis

2.2. Photo-fermentation

2.3. Dark-fermentation.

2.4. Two-stage process with integration of dark- and photo-fermentation

2.5. Substrates for biohydrogen production

3. Constraints of $\mathrm{H}_{2}$-producing bioprocesses

3.1. Chemical reactions related limitation.

3.2. Reactor design related limitation.

4. Enhancement of biohydrogen production.

4.1. Physical pretreatments and operating conditions.

4.2. Modified reactor configurations

4.3. Novel bacterial strains

4.4. Genetic manipulations

5. Conclusion

References.

\section{Introduction}

The world population and consequently energy demands seem to grow following an exponential rate (Antonopoulou et al., 2007). The impending shortage of energy resources together with the environmental fall off due to unreasonable use of fossil fuels, leading many scientists to the search for alternative energy sources (Antonopoulou et al., 2007). Among others, research has focused on the hydrogen production field, either by physicochemical or biological methods. Hydrogen is a clean (Kovács et al., 2006) and environmentally friendly fuel (Shin et al., 2010), which produces water instead of greenhouse gases when combusted. It can be produced by renewable raw materials, such as organic wastes, and possesses a high-energy yield $(122 \mathrm{~kJ} / \mathrm{g})$ due to its light weight and which is 2.75 times greater than the hydrocarbon (Han and Shin, 2004), and it could be directly used to produce electricity through fuel cells (Lay et al., 1999; Benemann, 1996).

Hydrogen has been an unrealized "fuel of the future" for over 30 years, but there are signs that hydrogen may finally become an important component of the energy balance of a global economy (Logan et al., 2002) arising out of the projection of fossil fuel shortfall towards the middle of 21 st century (Kotay and Das, 2008). The demand for hydrogen is not limited to utilization as a source of energy but hydrogen gas is also a widely used on the production of chemicals, for hydrogenation of fats and oils in food industry for margarine producion, processing steel and also for the desulphurization and re-formulation of gasoline in refineries (Kapdan and Kargi, 2006). Low-cost hydrogen based fuel cells, which have been expensive or not readily available, are now entering commercial production and are finding applications in residential housing and buses. Despite the "green" nature of hydrogen as a fuel, it is still primarily produced from 
nonrenewable sources such as natural gas and petroleum hydrocarbons via steam reforming. In order for hydrogen to become a more sustainable and green source of energy, hydrogen must be produced by biological or biochemical reaction pathways (Logan et al., 2002; Han and Shin, 2004).

This paper review shall presently address the biohydrogen production advance from a Green Engineering by revisiting the essential biohydrogen generation processes, identifying the key limitations to a more efficient biohydrogen production and thereafter probing into some selected recent research findings which report the enhancement realized in the overall rates and yields of biohydrogen production.

\subsection{The biohydrogen alternative}

Biological hydrogen production and utilization has received special attention during the last decade (Fig. 1). Biohydrogen may be produced by cyanobacteria and algae through biophotolysis of water (Asada and Miyake, 1999) or by photosynthetic and chemosynthetic-fermentative bacteria. Some species of cyanobacteria naturally produce hydrogen gas as a byproduct of anaerobic fermentation at night using fixed-carbon compounds (Damian et al., 2008). Also, anaerobic fermentative bacteria produce hydrogen without photoenergy, and so the cost of hydrogen production is 340 times lower than the photosynthetic process.

The main source of hydrogen during a biological, fermentative process is carbohydrates, which are very common in plant tissues, either in the form of oligosaccharides or as their polymers, cellulose, hemicellulose and starch. Thus, the biomass of certain plants with high content in carbohydrates has been earnestly considered as a very promising substrate for biohydrogen production. In addition, using properly selected microorganisms, many rural residues and waste organic materials can be processed and degraded for biohydrogen production as well (Venkata Mohan, 2010). Mohanakrishna et la. (2010) verified that domestic sewage supplementation as co-substrate with composite vegetable based market waste could increase hydrogen production at fermentative process and maintain good buffering microenvironment that supports fermentation process and in addition provides micro-nutrients, organic matter and microbial biomass. The maximum theoretical hydrogen yield is 4 moles per mole of utilized carbohydrates, expressed as glucose equivalents when carbohydrates are used as substrate (Nandi and Sengupta, 1998; Logan et al., 2002).

Fermentative hydrogen production from biomass can be achieved either by using mixed acidogenic microbial cultures or a pure culture of a saccharolytic strain. Ruminococcus albus is a non spore-forming, obligatory anaerobic bacterium, the natural habitat of which is the first stomach (rumen) of the ruminants. It produces extracellular hydrolytic enzymes (exoglucanases and endoglucanases), which break down cellulose and hemicellulose, whereas it cannot break down pectin and starch (Antonopoulou et al., 2007). The oligosaccharides produced from cellulose and hemicellulose degradation cellobiose, glucose and the respective pentoses, xylose and arabinose, are further metabolized (Lou et al., 1997). 
Logan et al. (2002) have analyzed the biological production of hydrogen from the fermentation of different substrates in batch tests using heat-shocked mixed cultures with two techniques: an intermittent pressure release method (Owen method) and a continuous gas release method using a bubble measurement device (respirometric method). Also, Lay et al. (2004) demonstrated optimal substrate concentration and $\mathrm{pH}$ for generating biohydrogen gas in composting enriched from heat-shocked by anaerobic microbes of cow compost. Under otherwise identical conditions, the respirometric method resulted in the production of $43 \%$ more hydrogen gas from glucose than the Owen method. The lower conversion of glucose to hydrogen using the Owen protocol may have been produced by repression of hydrogenase activity from high partial pressures in the gastight bottles. High conversion efficiencies were consistently obtained with heat-shocked soils taken at different times and those stored for up to a month. Hydrogen gas composition was consistently in the range of 60-64\% for the glucose-grown cultures during logarithmic growth but declined in the stationary cultures. Overall, biohydrogen conversion efficiencies for glucose cultures were $23 \%$ based on $4 \mathrm{~mol}$ of hydrogen/mol of glucose. Logan et al. (2002) noted that the biohydrogen conversion efficiencies were similar for sucrose $(23 \%)$ and lower for molasses $(15 \%)$ but were much lower for lactate $(0.50 \%)$ and cellulose $(0.075 \%)$.

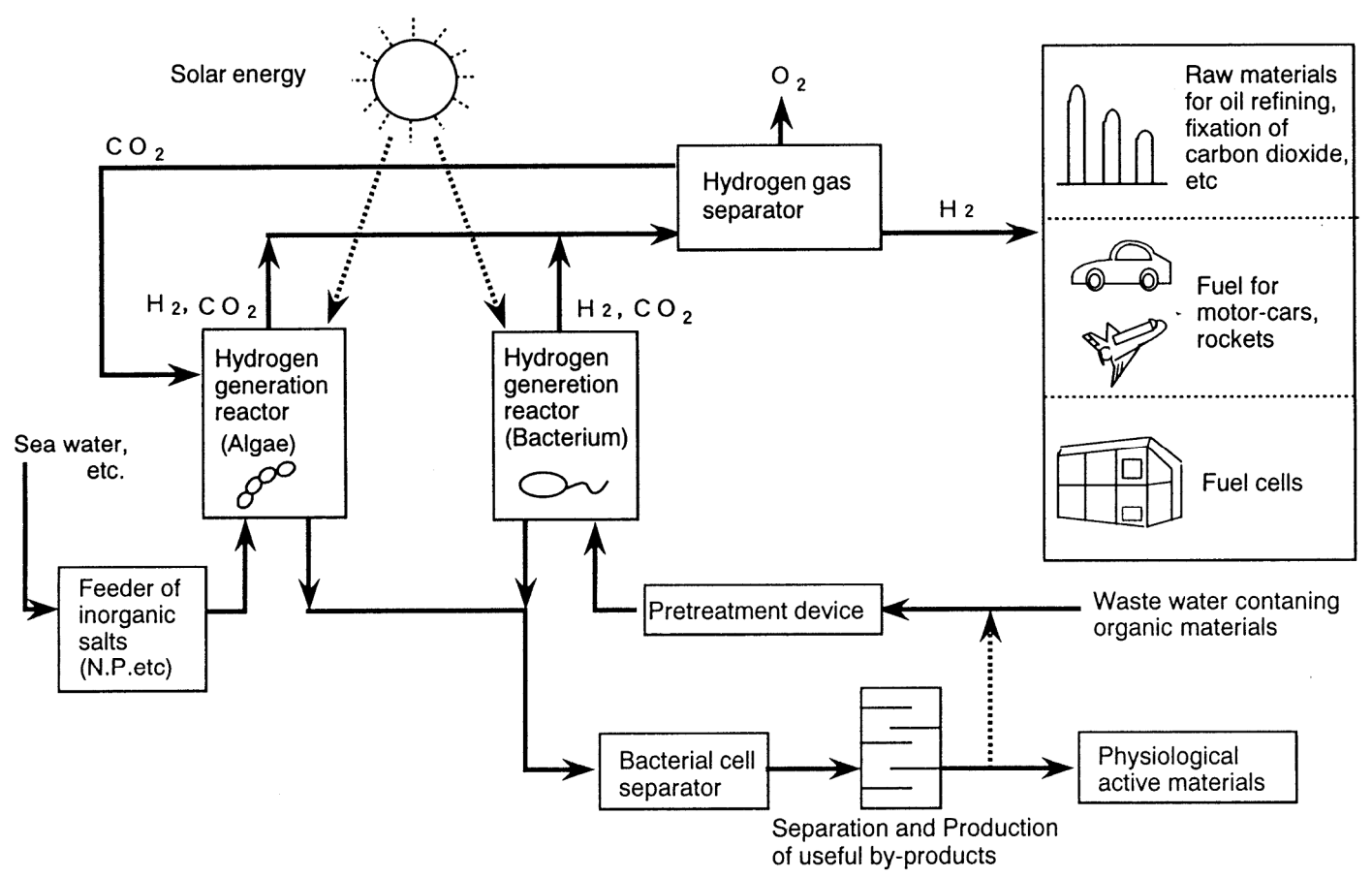

Fig. 1. Concept of biological hydrogen production and utilization. (Miyake et al., 1999)

\subsection{Green technology and biohydrogen production}

With sustainable development and waste minimization issues, biohydrogen gas production from renewable sources, also known as "green technology" has received considerable attention in recent years (Chang et al., 2006; Kapdan and Kargi, 2006). Biologically hydrogen can be produced by the photosynthetic and fermentative methods which are more environmental friendly and less energy intensive compared to 
chemical process (Kim et al., 2004; Shin et al., 2010). The production of biohydrogen hence fits very well with the emerging "Green Chemistry" concept. We now outline the salient characteristics of Green Chemistry and Green Engineering which host hydrogen production bioprocesses.

Green Chemistry (or, environmentally benign chemistry) is the utilization of a set of principles that reduces or eliminates the use or generation of hazardous substances in the design, manufacture and application of chemical products (Kidwai and Mohan, 2005). In practice, Green Chemistry is taken to cover a much broader range of issues than the definition suggests. As well as using and producing better chemicals with less waste, Green Chemistry also involves reducing other associated environmental impacts, including reduction in the amount of energy used in chemical processes (Kidwai and Mohan, 2005). Anastas and Warner (1998) have developed 'The Twelve Principles of Green Chemistry' that serve as valuable and benchmark guidelines for practicing chemists, researchers and engineers in developing and assessing how green a synthesis, compound, process or technology is. These principles are outlined below (Anastas and Warner, 1998).

Prevention: It is better to prevent waste than to treat or clean up waste after it has been created.

Atom Economy: Synthetic methods should be designed to maximize the incorporation of all materials used in the process into the final product.

Less Hazardous Chemical Syntheses: Wherever practicable, synthetic methods should be designed to use and generate substances that possess little or no toxicity to human health and the environment.

Designing Safer Chemicals: Chemical products should be designed to effect their desired function while minimizing their toxicity.

Safer Solvents and Auxiliaries: The use of auxiliary substances (solvents, separation agents, etc.) should be made unnecessary wherever possible and innocuous when used.

Design for Energy Efficiency: Energy requirements of chemical processes should be recognized for their environmental and economic impacts and should be minimized. If possible, synthetic methods should be conducted at ambient temperature and pressure.

Use of Renewable Feedstocks: A raw material or feedstock should be renewable rather than depleting whenever technically and economically practicable.

Reduce Derivatives: Unnecessary derivatization (use of blocking groups, protection/deprotection, and temporary modification of physical/chemical processes) should be minimized or avoided if possible, because such steps require additional reagents and can generate waste.

Catalysis: Catalytic reagents (as selective as possible) are superior to stoichiometric reagents.

Design for Degradation: Chemical products should be designed so that at the end of their function they break down into innocuous degradation products and do not persist in the environment.

Real-Time Analysis for Pollution Prevention: Analytical methodologies need to be further developed to allow for real-time, in-process monitoring and control prior to the formation of hazardous substances. 
Inherently Safer Chemistry for Accident Prevention: Substances and the form of a substance used in a chemical process should be chosen to minimize the potential for chemical accidents, including releases, explosions and fires.

Green chemistry is also and intimate and essential part of Green Engineering. The definitions of Green Chemistry and Green Engineering share many commonalities, and the application of both chemistry and engineering principles is needed to advance the goals of environmental sustainability (Kirchhoff, 2003). A working definition of Green Engineering proposed in Kirchhoff (2003) is the design, commercialization, and use of processes and products that are feasible and economical while minimizing pollution at the source and risk to human health and the environment. The link between Green Chemistry and Green Engineering is strong in ensuring that inputs and outputs, both for materials and energy flows and budgeting, are as inherently safe as possible. Whilst Green Chemistry focuses on the design of chemical products and processes that reduce or eliminate the use and generation of hazardous substances, it also lays down the ground plan for the design of the Green Engineering technologies needed to implement sustainable products, processes, and systems (Kirchhoff, 2003). The reader is in point of fact directed to the following excellent publications which present and discuss the salient aspects of Green Chemistry and Green Engineering: Anastas and Kirchhoff (2002), Anastas and Zimmerman (2003), Anastas and Lankey (2000), Clark (2006), Höfer and Bigorra (2007), Kirchhoff (2003), Lankey and Anastas (2002), Ran et al. (2008), Tang et al. (2008) and Tundo et al. (2000).

Over the last decade, Green Chemistry has convincingly demonstrated how fundamental scientific methodologies may be devised and be applied to protect human health and the environment in an economically beneficial manner (Anastas and Kirchhoff, 2002). Significant progress is being made in several key research areas, such as biosynthesis, biochemical engineering, biocatalysis, photocatalysis, heterogeneous catalysis, the design of safer chemicals and environmentally benign solvents, sonochemistry, microwave assisted polymerization and the development of renewable feedstocks. Biohydrogen production which is essentially a novel category of biochemical processes in the renewable energy sector is an emerging tentacle of Green Engineering in terms of design for energy efficiency, use of renewable feedstocks and novel bioprocesses, as more fully evidenced by the studies reported downstream in this review. However, it is also crucial to perform Life Cycle Assessment (LCA) to quantitatively know how green is a chemical reaction or a general process to extract reliable conclusions about its sustainability (Domènech et al., 2002).

\section{Biohydrogen production methods}

Processes for biological hydrogen production operate at ambient temperatures and pressures, and are expected to be less energy intensive than thermochemical methods of hydrogen production (Manish and Banerjee, 2008). Hydrogen can be produced biologically by biophotolysis (direct and indirect), photo-fermentation and dark-fermentation or by a combination of these processes (such as integration of darkand photo-fermentation, or biocatalyzed electrolysis). At laboratory scale biological hydrogen has been produced continuously (Manish and Banerjee, 2008); however biohydrogen production at commercial scale is not reported in the literature and challenges regarding process scale up remain (Hawkes et al., 2002). 
The biohydrogen production are fundamentally dependent upon the presence of a hydrogen $\left(\mathrm{H}_{2}\right)$ producing enzyme. These enzymes catalyze the chemical reaction $2 \mathrm{H}++2 \mathrm{e}^{-} \leftrightarrow \mathrm{H}_{2}$. A survey of all presently known enzymes capable of hydrogen evolution shows that they contain complex metallo-clusters as active sites (Manish and Banerjee, 2008). At present three enzymes carrying out this reaction are known; nitrogenase, $\mathrm{Fe}$-hydrogenase and $\mathrm{NiFe}$-hydrogenase (Hallenbeck and Benemann, 2002). Fe-hydrogenase enzyme is used in the biophotolysis processes whereas photo-fermentation processes utilize nitrogenase. A brief description, condensed from Manish and Banerjee (2008) of these processes is provided below (Photo-fermentation technology).

In resume, the major bioprocesses utilized for hydrogen gas production can be classified in three categories:

1. Biophotolysis of water by algae

2. Dark-fermentative hydrogen production during acidogenic phase of anaerobic digestion of organic matter

3. Two stage dark/photo-fermentative production of hydrogen

\subsection{Biophotolysis}

The direct biophotolysis method is similar to the processes found in plants and algal photosynthesis. In this process solar energy is directly converted to hydrogen via photosynthetic reactions $2 \mathrm{H}_{2} \mathrm{O}+h v \rightarrow 2 \mathrm{H}_{2}+\mathrm{O}_{2}$ where $h v$ represent the energy from a photon in light ( $h$ is the Planck constant and $v$ is the frequency of the light). The indirect biophotolysis method circumvents problems of sensitivity of the hydrogen evolving process by separating temporally and/or spatially oxygen evolution and hydrogen evolution. Thus, indirect biophotolysis processes involve separation of the $\mathrm{H}_{2}$ and $\mathrm{O}_{2}$ evolution reactions into separate stages, coupled through $\mathrm{CO}_{2}$ fixation/evolution. Our survey of literature shows that cyanobacteria are the only bacteria capable of performing oxygenic photosynthesis in which they harness solar energy and convert it into chemical energy stored in carbohydrates, and under specific conditions, cyanobacteria can use solar energy to produce also molecular hydrogen (Allahverdiyeva et al., 2010). Thus, cyanobacteria have the unique characteristics of using $\mathrm{CO}_{2}$ in the air as a carbon source and solar energy as an energy source. The cells take up $\mathrm{CO}_{2}$ first to produce cellular substances, which are subsequently used for hydrogen production. The overall mechanism of hydrogen production in cyanobacteria can be represented by the following reactions: $12 \mathrm{H}_{2} \mathrm{O}+6 \mathrm{CO}_{2}+h v \rightarrow \mathrm{C}_{6} \mathrm{H}_{12} \mathrm{O}_{6}+6 \mathrm{O}_{2}$ and $\mathrm{C}_{6} \mathrm{H}_{12} \mathrm{O}_{6}+12 \mathrm{H}_{2} \mathrm{O}+h v \rightarrow 12 \mathrm{H}_{2}+6 \mathrm{CO}_{2}$.

\subsection{Photo-fermentation}

Photosynthetic bacteria evolve molecular hydrogen catalyzed by nitrogenase under nitrogen-deficient conditions using light energy and reduced compounds (organic acids) (Levin et al., 2004). These bacteria themselves are not powerful enough to split water. However, under anaerobic conditions, these bacteria are able to use simple organic acids, like acetic acid as electron donors (Manish and Banerjee, 2008). These electrons are transported to the nitrogenase by ferredoxin using energy in the form of 
adenosine triphosphate (ATP). When nitrogen is not present, this nitrogenase enzyme can reduce proton into hydrogen gas again using extra energy in the form of ATP (Akkerman et al., 2002). The overall reaction of hydrogen production can be given as $\mathrm{C}_{6} \mathrm{H}_{12} \mathrm{O}_{6}+6 \mathrm{H}_{2} \mathrm{O}+h v \rightarrow 12 \mathrm{H}_{2}+6 \mathrm{CO}_{2}\left(\Delta \mathrm{G}_{\mathrm{o}}=+3.2 \mathrm{~kJ}\right)$. Recently, Gadhamshetty et al. (2008) developed a kinetic model for the photo-fermentative biohydrogen production to predict the dynamics of the process. The proposed model contained 17 parameters to describe cell growth, substrate consumption, and hydrogen evolution as well as inhibition of the process by biomass, light intensity, and substrate. Based on sensitivity analyses performed with the validated model, only six of the 17 parameters were found to be significant.

The fermentation process for hydrogen production has been widely reported but there is observably a lack of information related to detailed kinetic studies. Our review of literature has shown that the kinetic analysis of biohydrogen production has been mostly performed using the modified Gompertz equation for fitting the experimental data of accumulative hydrogen production (Lay, 2001; Wu and Lin, 2004; Fang et al., 2005; Van Ginkel et al., 2005; Mu et al., 2006; Gadhamshetty et al., 2010). The modified Gompertz equation is:

$$
H(t)=P \times \exp \left\{-\exp \left[\frac{R_{m} e}{P}(\lambda-t)+1\right]\right\}
$$

where $H(t)$ is the accumulative hydrogen production (l) during the fermentation time $t(\mathrm{~h}), P$ the (maximum) hydrogen production potential (1), $R_{m}$ the maximum production rate $(1 / \mathrm{h}), \lambda$ the lag-phase time $(\mathrm{h})$, and $e$ is 2.7182818 . The values of $P, R_{m}$ and $\lambda$ are normally determined by best fitting the experimental hydrogen producing data using a suitable software (Fang et al., 2002).

\subsection{Dark-fermentation}

Dark-fermentation among the processes is the most powerful system because of a relatively higher rate of hydrogen production, and many researchers have studied biohydrogen production by fermentative bacteria, such as Escherichia coli (Yoshida et al., 2005), Enterobacter species (Palazzi et al., 2000; Kurokawa and Tanisho, 2005; Zhang et al., 2005; Shin et al., 2007) and Clostridium species (Jo et al., 2008). Many studies on hydrogen production have been performed using facultative anaerobes because of a difficulty in maintaining the strict anaerobic condition, which is necessary for obligate bacteria. Strict anaerobes, such as Clostridium species, are very sensitive to trace amounts of dissolved oxygen, resulting in the necessity of expensive reducing agents to be added in the culture medium (Shin et al., 2010). However, facultative anaerobes, such as Enterobacter species, are less sensitive to dissolved oxygen, and the activity of the enzyme involved in hydrogen production can be rapidly recovered from the oxygen damage when depleted in the culture medium (Shin et al., 2010).

The majority of microbial hydrogen production is driven by the anaerobic metabolism of pyruvate, formed during the catabolism of various substrates. The breakdown of pyruvate is catalyzed by one of two enzyme systems (Hallenbeck and Benemann, 2002) 
given below. The metabolic pathways, types and function of enzymes involved in the biological hydrogen production for different microbial processes are discussed in much more details in the following excellent review articles: Das and Veziroglu (2001), Asada and Miyake (1999), Miyake et al. (1999), Ghirardi et al. (2000), Kruse et al. (2005), Manish and Banerjee (2008). Carbohydrates are the preferred substrate for hydrogen-producing fermentations. Glucose yield different amount of hydrogen depending on the fermentation pathway and end-product(s).

Pyruvate: formate lyase

Pyruvate $+\mathrm{CoA} \rightarrow$ acetyl-CoA + formate

Pyruvate: ferredoxin oxido reductase

Pyruvate $+\mathrm{CoA}+2 \mathrm{Fd}($ ox $) \rightarrow$ acetyl-CoA $+\mathrm{CO}_{2}+2 \mathrm{Fd}($ red $)$

\subsection{Two-stage process with integration of dark- and photo-fermentation}

In fermentation, complete oxidation of 1 mole of glucose yields 12 moles of hydrogen. However, complete oxidation of glucose into hydrogen and carbon dioxide is not possible as the corresponding reaction is not feasible thermodynamically $\left(\mathrm{C}_{6} \mathrm{H}_{12} \mathrm{O}_{6}+\right.$ $6 \mathrm{H}_{2} \mathrm{O} \rightarrow 12 \mathrm{H}_{2}+6 \mathrm{CO}_{2}, \Delta \mathrm{G}_{\mathrm{o}}=+3.2 \mathrm{~kJ}$ ). With external energy supply (photon-energy in photo-fermentation) theoretically 12 moles of hydrogen per mole of glucose can be produced. However, this process cannot be operated in the absence of light. On the other hand, in the absence of external energy (in the case of dark-fermentation), oxidation of glucose by fermentative bacteria results in other by-products also and only a maximum of 4 moles of hydrogen are produced per mole of glucose consumption $\left(\mathrm{C}_{6} \mathrm{H}_{12} \mathrm{O}_{6}+2 \mathrm{H}_{2} \mathrm{O} \rightarrow 4 \mathrm{H}_{2}+2 \mathrm{CO}_{2}+2 \mathrm{CH}_{3} \mathrm{COOH},\left(\Delta \mathrm{G}_{\mathrm{o}}=-206 \mathrm{~kJ}\right)\right.$. Acetate produced in the dark-fermentation stage can be oxidized by photosynthetic bacteria to produce hydrogen $\left(\mathrm{CH}_{3} \mathrm{COOH}+2 \mathrm{H}_{2} \mathrm{O}+h v \rightarrow 4 \mathrm{H}_{2}+2 \mathrm{CO}_{2},\left(\Delta \mathrm{G}_{\mathrm{o}}=+104 \mathrm{~kJ}\right)\right.$. Hence, continuous production of hydrogen at maximum yield can be achieved by integrating dark- and photo-fermentation methods. Yang et al. (2010) recently reported enhanced biohydrogen production rates by integrating dark-fermentation with photo-fermentation process for pretreated corncob. In the first step, the maximum biohydrogen yield and rate from corncob by dark-fermentation was $120.3 \mathrm{ml} \mathrm{H}_{2} / \mathrm{g}$ corncob and $150 \mathrm{ml} \mathrm{H}_{2} / \mathrm{l} / \mathrm{h}$, respectively. In the second step, a hydrogen yield of $713.6 \mathrm{ml} \mathrm{H}_{2} / \mathrm{g}$ COD was obtained from digesting the effluent of dark-fermentation by photosynthetic bacteria.

\subsection{Substrates for biohydrogen production}

Hydrogen gas shows great promise as a non-polluting fuel, but to reduce carbon dioxide releases hydrogen gas will need to be produced from renewable sources (Van Ginkel et al., 2005; Refaat and El Sheltawy, 2008). Most hydrogen gas produced is obtained from thermocatalytic and gasification processes using natural gas $(50 \%)$, petroleum-derived napthenes and distillates (30\%), and coal (18\%), with the remainder from electricity (2\%) (Van Ginkel et al., 2005).

Substrates are present in very large quantities as products or waste from agriculture, crop residues, the food industry and market waste, animal waste and organic matter of municipal solid waste (Forster-Carneiro et al., 2008) and this substrate is readily 
utilized for biohydrogen production. Biohydrogen production from the fermentation of renewable carbohydrate-rich and non-toxic raw materials (Kapdan and Kargi, 2006) is one promising alternative although the use of commercially produced food products, such as corn and sugar, is not yet economical (Benemann, 1996). Substrates used for biohydrogen production have ranged from simple sugars such as glucose (Li et al., 2008), sucrose (Antonopoulou et al., 2007), starch containing waste such as cassava wastewater (Sangyoka et al., 2007), dairy wastewater (Venkata Mohan et al., 2007a), sweet potato starch residue (Yokoi et al., 2001), sugarcane bagasse (Patra et al., 2008), cheese whey (Davila-Vazquez et al., 2009) and food waste (Ruknongsaeng et al., 2005). Others substrates for biohydrogen production were showed in Table 1. According Holladay and collaborates (2009) the starch agricultural and food industry waste must by hydrolyzed to glucose or maltose, followed by conversion to organic acids and finally hydrogen; cellulose agricultural and food industry waste must be finely ground and go through delignification, then it is processed as starch; and carbohydrate rich industrial waste may require pretreatment for removal of undesirables and for nutritional.

\section{Table 1}

Substrates for biohydrogen production

\begin{tabular}{|l|l|}
\hline $\begin{array}{l}\text { Substrates for biohydrogen } \\
\text { production }\end{array}$ & References \\
\hline Cassava wastewater & Sangyoka et al. (2007) \\
\hline Cellulose & $\begin{array}{l}\text { Lay (2001); Wang et al. (2008); Taguchi et al. } \\
\text { (2007a); }\end{array}$ \\
\hline Cellulose and wastewater & Liu et al. (2003) \\
\hline Cheese & Davila-Vazquez et al. (2009); Castelló et al. (2009) \\
\hline Chemical wastewater & Venkata Mohan et al. (2007a) \\
\hline Coffee wastewater & Dinsdale et al. (1997) \\
\hline Composting & Sparling et al. (1996); Fan et al. (2004) \\
\hline Cornstalk wastes & Zhang et al. (2007a) \\
\hline Corncob & Yang et al. (2010) \\
\hline Glucose & $\begin{array}{l}\text { Li et al. (2008); Mu et al. (2009); Fang and Liu ( } \\
\text { 2002) }\end{array}$ \\
\hline Glucos-Peptone & Li et al. (2010) \\
\hline Food waste & $\begin{array}{l}\text { Ruknongsaeng et al. (2005); Wu and Lin (2004); } \\
\text { Han and Shin (2004); Han et al. (2005) }\end{array}$ \\
\hline Food waste-sludge & Kim et al. (2004) \\
\hline Fruit and vegetable waste & Bouallagui et al. (2004) \\
\hline Malate & Gadharnshetty et al. (2008) \\
\hline Market waste & Mohanakrishna et al. (2010) \\
\hline Microalgae & $\begin{array}{l}\text { Melis et al. (2007); Beer et al. (2009); Ghirardi et } \\
\text { al. (2000) }\end{array}$ \\
\hline Molasses wastewater & Wu and Lin (2004) \\
\hline Olive mill effluents & Raposo et al. (2004) \\
\hline & \\
\hline
\end{tabular}




\begin{tabular}{|l|l|}
\hline $\begin{array}{l}\text { Organic fraction of municipal } \\
\text { solid wastes }\end{array}$ & $\begin{array}{l}\text { Okamoto et al. (2000); Valdez-Vazquez et al. } \\
(\mathbf{2 0 0 6}) ; \text { Ueno et al. (2006); Lay et al. (2009) }\end{array}$ \\
\hline Palm oil mill & O-Thong et al. (2007) \\
\hline Pineapple waste & Ruknongsaeng et al. (2005) \\
\hline Sorghum biomass & Antonopoulou et al. (2007) \\
\hline Sludge & $\begin{array}{l}\text { Zhu and Beland (2006); Wu et al. (2002); Lee et } \\
\text { al. (2004); Lay et al. (2003); Kotsopoulos et al. } \\
(\mathbf{2 0 0 6 ) ; ~ K o t a y ~ a n d ~ D a s ~ ( 2 0 0 9 ) ; ~ G u o ~ e t ~ a l . ~ ( 2 0 0 8 ) ; ~} \\
\text { Chang and Lin (2004); Cai et al. (2004) }\end{array}$ \\
\hline Sucrose & Lin and Jo (2003); Chen and Lin (2003) \\
\hline Sugarcane bagasse & Patra et al. (2008) \\
\hline Sweet potato starch residue & Yokoi et al. (2001) \\
\hline Wet Sludge & Wee and Verstraete (1998) \\
\hline Wastewaters & $\begin{array}{l}\text { Van Ginkel et al. (2005); Zheng et al. (2009); } \\
\text { Venkata Mohan et al. (2007a); Fang et al. (2005); }\end{array}$ \\
\hline $\begin{array}{l}\text { Various wastes and } \\
\text { wastewaters }\end{array}$ & Logan et al. (2002); Kapdan and Kargi (2006) \\
\hline
\end{tabular}

Wastewaters show great potential for economical production of hydrogen because producing a product from a waste could reduce waste treatment and disposal costs (Van Ginkel et al., 2005). Hydrogen has so far been produced from the organic fraction of municipal solid wastes (Okamoto et al., 2000) and cellulose (Lay, 2001). Batch tests using various wastes and wastewaters suggest that hydrogen production is more efficient from carbohydrates than other materials (Logan et al., 2002). Simple sugars, such as sucrose and glucose, are converted at elevated temperatures to hydrogen at high conversion efficiencies. Yields of $28 \%$ were obtained with glucose, and $26 \%$ with sucrose, at $30{ }^{\circ} \mathrm{C}$, while hydrogen produced from molasses, lactate, and cellulose were $15 \%, 0.5 \%$ and $0.075 \%$, respectively (Logan et al., 2002). These results indicate that high-carbohydrate wastewaters will be seemingly the most useful for industrial production of hydrogen. Wu and Lin (2004) have conducted batch experiments to convert molasses wastewater (10-160 g chemical oxygen demand (COD)/l) into hydrogen at $35^{\circ} \mathrm{C}$ at various $\mathrm{pH}(4-8)$. The maximum hydrogen productivity (HP) and

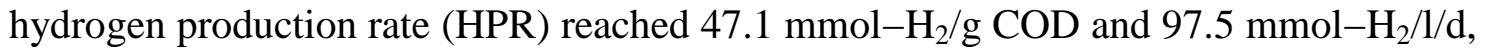
respectively, at a substrate concentration of $40 \mathrm{~g} \mathrm{COD} / \mathrm{l}$ and $\mathrm{pH} 6.0$, and the methane-free biogas contained up to $50 \%$ (v/v) of hydrogen. O-Thong et al. (2007) seeded thermophilic microflora into an anaerobic sequencing batch reactor for hydrogen production from palm oil mill effluent (POME) and supplemented the reaction mixture with nitrogen, phosphorus and iron sources for biostimulants. O-Thong et al. (2007) noted that the nutrient supplementation strategy had increased the bacterial diversity in the reactor and promoted in particular the growth of hydrogen-producing bacteria Thermosaccharolyticum which ultimately increased the hydrogen production yield from 1.60 to $2.24 \mathrm{~mol} \mathrm{H}_{2} / \mathrm{mol}$ hexose and hydrogen production rate from 4.4 to $6.11 \mathrm{H}_{2} / 1 \mathrm{POME} / \mathrm{d}$.

Cellulose is a predominant constituent of agricultural waste and waste generated by the pulp and paper industry. To generate hydrogen directly from cellulose materials using dark fermentation requires expensive pretreatment processes such as delignification and hydrolysis to dissolve organic matter from a lignocellulose complex (Taguchi et al., 
1996). Lay (2001) investigated the potential of producing hydrogen from microcrystalline cellulose using mesophilic digestion with heat-shocked sludge. With a 4-day lag, a maximum hydrogen yield of $4.36 \mathrm{mg} / \mathrm{g}$ cellulose was produced from suspensions containing $12: 5 \mathrm{~g}$ cellulose/l. The metabolites were predominantly alcohols, followed by volatile fatty acids. Liu et al. (2003) determined that their mixed culture comprising microbes closely affiliated with the genus Thermoanaerobacterium produced hydrogen that peaked at 7:56 $\mathrm{mg} \mathrm{H}_{2} / \mathrm{g}$ cellulose and a maximum rate of 21:2 $\mathrm{mg} \mathrm{H}_{2} / \mathrm{g}$ VSS/d from a $5 \mathrm{~g}$ cellulose/l suspension maintained at $\mathrm{pH} 6.5$ and $55^{\circ} \mathrm{C}$. The metabolites observed were primarily acetate, butyrate, and ethanol.

\section{Constraints of $\mathrm{H}_{2}$-producing bioprocesses}

\subsection{Chemical reactions related limitation}

For hydrogen generation, the current biomass technologies include: gasification, pyrolysis, liquefaction, hydrolysis and conversion to liquid fuels by supercritical extraction, etc. followed in some cases by reformation, and biological hydrogen production (Holladay et al., 2009). The gasification technology of biomass or wastewater is commonly used in many processes but the biological hydrogen has substantially increased over the last several years. The sewage sludge of wastewater treatment plants is composed largely of organic matters like carbohydrates and proteins (Weemaes and Verstraete, 1998; Xiao and Liu, 2009) and the anaerobic digestion technique has been employed to treat sludge and obtain methane (Reith et al., 2003). Hydrogen is an intermediate product of the anaerobic sludge digestion, but unstable, because it will be quickly consumed by hydrogen-consuming bacteria, such as methanogens and sulpate-reducing bacteria. In order to harvest hydrogen from anaerobic sludge digestion, the activity of consuming-hydrogen bacteria must be inhibited and stopped at the hydrogen and acetic acid forming stage and the consumption of hydrogen must be blocked (Hawkes et al., 2002). In cornstalk wastes conversion into hydrogen, the acetate, propionate, butyrate, and the ethanol were main by-products in the metabolism of hydrogen fermentation. Also, the test results showed that the acidification pretreatment of the substrate plays a crucial role in conversion of the cornstalk wastes into biohydrogen gas by the cow dung composts generating hydrogen (Zhang et al., 2007a). Additionally, the engineering challenges of scale up and a shift in the type of biomass substrates from starch-based food crops to lignocellulosic feedstock and wastes that are economically and environmentally less costly to produce, yet more difficult to biochemically process, present technical challenges that are inherent to the biohydrogen energy promise (Jones, 2008).

\subsection{Reactor design related limitation}

Biohydrogen production by anaerobic fermentation has attracted worldwide attention owing to the fact that hydrogen can be produced substantially at a high rate form renewable organic matters (Benemann, 1996). Biohydrogen production systems are to become commercially competitive they must be able to synthesize $\mathrm{H}_{2}$ at rates that are sufficient to power fuel cells of sufficient size to do practical work (Logan, 2010).

The studies on continuous fermentative hydrogen production in the laboratory-scale had been conducted using suspended-cell systems and immobilized-cell systems since 
1980s (Chen and Lin, 2003; Fan et a., 2006). The HPR has been considered as an important index to evaluate the performance of continuous hydrogen-producing processes (Chang et al., 2002). However, continuous stirred tank reactor (CSTR) process, a typical representative of suspended-cell systems, usually exhibits poor performance in HPR since it is unable to maintain high levels of hydrogen-producing biomass at a short hydraulic retention time (HRT) due to its intrinsic structure (Zhang et al., 2007a). To achieve satisfactory HPR, immobilized-cell systems have become popular alternatives to suspended-cell systems for continuous biohydrogen production since they are more capable of maintaining higher biomass concentration even at lower HRTs (Wu et al., 2002). More recent studies by other authors conclude that, at low hidraulic retention time, acidogenic anaerobic digestion of organic waste reaches top speeds of hydrogen production, while contributing to the elimination of contaminating waste (Kapdan and Kargi, 2006; Kotsopoulos et al., 2006; Kyazze et al., 2005).

\section{Enhancement of biohydrogen production}

Under anaerobic conditions, hydrogen is produced as a by-product during conversion of organic wastes into organic acids which are then used for methane generation. Anaerobic digestion allows the stabilization of the waste disposal or in conjunction with hydrogen production at rates higher than that of other biological processes (Lee et al., 2004; Valdez-Vazquez et al., 2006) and conform a steady-state model for biological hydrogen production in a fermentation process (Whang et al., 2006). In the acidogenic phase of anaerobic digestion of wastes can be manipulated to improve hydrogen production. Photosynthetic processes include algae which use $\mathrm{CO}_{2}$ and $\mathrm{H}_{2} \mathrm{O}$ for hydrogen gas production. However, the rate and yield of $\mathrm{H}_{2}$ production has been found to be relatively low (Kapdan and Kargi, 2006; Das, 2009) and hence the biohydrogen technology has been thoroughly researched (Rachman et al., 1998; Levin et al., 2004).

Currently, laboratory-scale studies on anaerobic hydrogen fermentation technology are being conducted by a large number of research groups in different countries over the world (Fang and Liu, 2002; Lin and Jo, 2003). This technology exhibits positive features in hydrogen production such as high production rate, low energy demand, easy operation and high sustainability. However, it is yet to compete with those thermochemical processes converting hydrogen from fossil fuels in cost, performance or reliability (Das and Veziroglu, 2001). As a result, current research of anaerobic hydrogen fermentation has been focused on improving microbial hydrogen conversion rate and unit volumetric production rate. The former could be achieved by screening efficient hydrogen-producing bacteria and optimizing the operational conditions, while the latter is substantially influenced by the reactor biomass retention. To achieve such purposes, immobilization processes of hydrogen-producing culture have become most popular and have been developed extensively, due to the elevated biomass retention as compared to suspended-cell systems (Chang and Lin, 2004). Low yields and the rates of hydrogen formation may additionally be overcome by selecting and using more effective organisms or mixed cultures, developing more efficient processing schemes, optimizing the environmental conditions, improving the light utilization efficiency and developing more efficient photo-bioreactors. Due to inhibition of biohydrogen production by oxygen and ammonium-nitrogen, microbial growth and hydrogen formation steps may need to be separated in order to improve the hydrogen productivity 
(Kapdan and Kargi, 2006). A possible alternative is to increase the production of hydrogen using chemical inhibitors of methanogenesis. Sparling and collaborates (1996) have shown how to apply low concentrations of acetylene $(0.5-1 \% \mathrm{v} / \mathrm{v})$ to reactor atmosphere, an effective method of preventing methanogenesis in reactors designed for hydrogen production. Another strategy that has been applied is the thermal shock treatment of the inoculum used (Lay et al., 2003).

Many bacteria contain enzymes (hydrogenases) that can produce hydrogen during the fermentation of a variety of substrates. ATP is produced by substrate-level or electron transport phosphorylation, but the ATP yields of fermentation are quite low as compared to those of aerobic oxidation reactions. Fermentation reactions can produce many different end products such as hydrogen, acetate, ethanol, and others. The hydrogen-acetate couple produces more ATP per mole of substrate than alcohols such as ethanol and butanol and is the energetically "preferred" bacterial fermentation product for a sugar (Logan et al., 2002). The accumulation of hydrogen and other degradation byproducts during fermentation, however, can make the hydrogen-acetate reaction unfavorable leading to solvent production. In mixed anaerobic cultures, the accumulation of hydrogen is normally balanced by rapid hydrogen consumption by methanogens resulting in little net hydrogen accumulation in the system, and the individual and interactive effects of $\mathrm{pH}$, temperature and glucose concentration on $\mathrm{H}_{2}$ production could be evaluated (Mu et al., 2009). If high concentrations of hydrogen are desired, a system must be designed to remove hydrogen before it can lead to repression of its production and to prevent interspecies hydrogen transfer leading to methanogenesis. The culture conditions that can adversely affect hydrogen production are only beginning to be studied and are therefore not so well-understood. Batch tests using mixed cultures have demonstrated that very low $\mathrm{pH}$ 's and high substrate concentrations can reduce biohydrogen production. Increasing the substrate loading increases relative production of volatile acids and decreases the $\mathrm{pH}$, which can shift the reactions to solvent production. Heat shocking has been used to reduce the concentration of nonspore forming bacteria such as methanogens, but the effect of this procedure on the storage of the material and the differences between different batches of mixed cultures has not been tested. Indeed, Venkata Mohan et al. (2008) have observed that heat-shock pretreatment $\left(100{ }^{\circ} \mathrm{C} ; 1 \mathrm{~h}\right)$ evaluated for selectively enriching the hydrogen producing mixed culture using dairy wastewater as substrate resulted in relatively low $\mathrm{H}_{2}$ yield. Furthermore, the optimization of nutritional and environmental conditions has also been demonstrated to play an important role in developing hydrogen producing bioprocesses and improving their performance (Kumar and Satyanarayana, 2007). Among various reaction constraints affecting the fermentation of organic substrates like food waste, a key factor is the adjustment of environmental conditions during the fermentation because various components of such substrates have different characteristics of degradation (Han and Shin, 2004). Moreover, given a selected substrate, its concentration appears to be critical in terms of hydrogen production, being in most cases a factor to be explored (Akutsu et al., 2009).

\subsection{Physical pretreatments and operating conditions}

With regards to $\mathrm{H}_{2}$ generation during anaerobic wastewater treatment whereby hydrolysis is the rate limiting step ( $\mathrm{Li}$ and Noike, 1992), thermal pretreatment, alkaline pretreatment, acidification (Zhang et al., 2007a), sterilization (Kotay and Das, 2009), 
microwave (Guo et al., 2008), steam-exploded straw by simultaneous saccharification and fermentation (Li and Chen, 2007) and ultrasonic pretreatment (Penaud et al., 1999; Xiao and Liu, 2009; Venkata Mohan et al., 2008) of the parent anaerobic inoculum have been strategies which help to accelerate the hydrolysis step reducing the impact of rate limiting step and augmenting the anaerobic digestion to enhance $\mathrm{H}_{2}$ generation (Zhu and Béland, 2006).

Xiao and Liu (2009) have assessed acid pretreatment, alkaline pretreatment, thermal pretreatment and ultrasonic pretreatment to enhance biohydrogen production from sewage sludge. Their experimental results showed that the four pretreatments could all increase the soluble chemical oxygen demand (SCOD) of sludge and decrease the dry solid (DS) and volatile solid (VS) because the pretreatments could disrupt the floc structure and even the microbial cells of sludge. Additionally, the results of batch anaerobic fermentation experiments demonstrated that all of the four pretreatments could select hydrogen-producing microorganisms from the microflora of sludge and enhance the hydrogen production such that the hydrogen yield of the alkaline pretreated sludge at initial $\mathrm{pH}$ of 11.5 was maximal at $11.68 \mathrm{ml} \mathrm{H}_{2} / \mathrm{g} \mathrm{VS}$ and that of the thermal pretreated sludge was second at $8.62 \mathrm{ml} \mathrm{H}_{2} / \mathrm{g}$ VS. Another study optimizes the pre-acidification conditions in the thermophilic and mesophilic digestion of instant-coffee-production wastewater in upflow anaerobic sludge blanket (UASB) reactors. In this case, the thermophilic pre-acidification stage was operated with $\mathrm{pH}$ control or with $1.5 \mathrm{~g} \mathrm{l}^{-1} \mathrm{NaHCO}_{3}$ added to the feed, at retention times of 24, 18, 15 and $12 \mathrm{~h}$. The results suggest that thermophilic/mesophilic two-stage system gave a consistent improvement in performance (measured, for example, as \% COD reduction) compared with the single-stage system (Dinsdale et al., 1997). Earlier, Cai et al. (2004) had performed batch tests to analyze influences of the alkaline pretreatment and initial $\mathrm{pH}$ value on biohydrogen production from sewage sludge. The experimental results of the impact of different initial $\mathrm{pH}$ on biohydrogen production showed that both the maximal hydrogen yield occurred and that no methane was detected in the tests of at the initial $\mathrm{pH}$ of 11.0. Additionally, the biohydrogen yield had increased from $9.1 \mathrm{ml}$ of $\mathrm{H}_{2} / \mathrm{g}$ of dry solids (DS) of the raw sludge to $16.6 \mathrm{ml}$ of $\mathrm{H}_{2} / \mathrm{g}$ of DS of the alkaline pretreated sludge. Hence, the results of Cai et al. (2004) clearly showed that biohydrogen production could be enhanced and maintained stable by the combination of the high initial $\mathrm{pH}$ and alkaline pretreatment.

Higher yields of hydrogen gas can be recovered from the microbial fermentation of organic substrates at high concentrations when interspecies hydrogen transfer to methanogens is prevented. Bearing this metabolic requirement in focus, Oh et al. (2003a) have used two techniques to limit methanogenesis in mixed cultures: heat treatment, to remove nonspore forming methanogens from an inoculum, and low $\mathrm{pH}$ during culture growth. It was found that high hydrogen gas concentrations (57-72\%) were produced in all tests and that heat treatment of the inoculum ( $\mathrm{pH} 6.2$ or 7.5) produced greater hydrogen yields than low $\mathrm{pH}$ (6.2) conditions with a nonheat-treated inoculum. Overall, the results of Oh et al. (2003a) showed that low pH was, without heat treatment, sufficient to control hydrogen losses to methanogens in mixed batch cultures and suggested that additional methods would need to be found to limit acetogenesis in order to increase hydrogen gas yields by batch cultures. With regards to operational control of $\mathrm{pH}$, Mohanakrishna et al. (2010) observed significant improvement in $\mathrm{H}_{2}$ production and substrate degradation upon supplementing the waste 
with domestic sewage, and much less variation in the outlet $\mathrm{pH}$ in supplementation experiments compared to normal operation. Supplementation of waste with co-substrate seemingly helps to maintain good buffering microenvironment supports fermentation process and in addition provides micro-nutrients, organic matter and microbial biomass.

Another non-solved problem about hydrogen production in anaerobic conditions is the usual controversy between mesophilic and thermophilic conditions of temperature. Although most of the published works are carried out around the mesophilic conditions, recent studies have shown that hydrogen was successfully produced under the thermophilic condition $\left(55^{\circ} \mathrm{C}, 6\right.$ months), whereas no stable hydrogen production was observed under the mesophilic condition using starch as substrate and digested sludge as inoculum (Akutsu et al., 2009). This point is critical in terms of hydrogen production and yield.

\subsection{Modified reactor configurations}

The reactor design and process configuration also have a bearing on the overall chemistry the hydrogen producing reactions. In this respect, researchers have also studied several new configurations of experimental set ups to optimize the hydrogen production rates and yields (Maag et al., 2009). The studied of feasibility of anaerobic digestion process in separate phases show then that the hydrogen production could continuously maintain and effluent with low concentrations of volatile fatty acids (VFA). Similar results have been obtained by other authors for the treatment of fruit and vegetable waste (Bouallagui et al., 2004); waste mills (Raposo et al., 2004) and municipal solid waste (Ueno et al., 2006). Remaining studies have developed a new carrier-induced granular sludge bed (CIGSB) bioreactor and it was shown to be very effective in hydrogen production (Lee et al., 2006). However, since mechanical agitation was not employed to enable sludge granulation, the CIGSB system might still encounter problems with poor mass transfer efficiency during prolonged operations. Lee et al. (2006) designed the CIGSB to improve the mixing efficiency of CIGSB for better biomass-substrate contact by adjusting the height to diameter (H/D) ratios of the reactor and by implementing appropriate agitation device. Reactor designs with a H/D ratio of 8 gave better $\mathrm{H}_{2}$ production performance with a $\mathrm{H}_{2}$ production rate of $6.87 \mathrm{l} / \mathrm{h} / \mathrm{l}$ and a $\mathrm{H}_{2}$ yield of $3.88 \mathrm{~mol} \mathrm{H}_{2} / \mathrm{mol}$ sucrose, suggesting that the effectiveness of $\mathrm{H}_{2}$ production in the CIGSB system can be enhanced by using a proper upflow velocity and physical configuration of the reactor. Lee et al. (2006) deepened their analysis and following the supply of additional mechanical agitation for CIGSB reactor at a H/D = 12 , sludge piston floatation was dampened and this lead to further increases in the $\mathrm{H}_{2}$ production rate and $\mathrm{H}_{2}$ yield to $9.31 \mathrm{l} / \mathrm{h} / \mathrm{l}$ and $4.02 \mathrm{~mol} \mathrm{H}_{2} / \mathrm{mol}$ sucrose, respectively. Ren et al. (2007) investigated optimal fermentation type and the operating conditions of anaerobic process in continuous-flow acidogenic reactors for the maximization of biohydrogen production using mixed cultures. They reported a maximum hydrogen production of up to $14.99 \mathrm{l} / \mathrm{d}$ for organic loading rate (OLR) of $86.1 \mathrm{~kg} \mathrm{COD} / \mathrm{m}^{3} / \mathrm{d}$.

Zhang et al. (2007b) have examined a new approach to immobilize mixed culture of hydrogen-producing bacteria by growing these on granular activated carbon in an anaerobic fluidized bed reactor, with the production of hydrogen assessed by the immobilized culture at a consistent $\mathrm{pH}$ of 4.0 and at a temperature of $37{ }^{\circ} \mathrm{C}$. It was 
observed that the hydrogen production rate and specific hydrogen production rate were linearly correlated to the effective OLR, which was calculated on the basis of organic loading and glucose conversion rate, giving the respective maximum rates of $2.36 \mathrm{l} / \mathrm{l} / \mathrm{h}$ and $4.34 \mathrm{mmol}-\mathrm{H}_{2} / \mathrm{gVSS} / \mathrm{h}$. Zhang et al. (2007b) concluded that a substantial quantity of retained biomass would enable the reactor to run at the high organic loading rates and thus enhance the production rates of hydrogen gas. Later, Zhang et al. (2008a) used biofilm sludge and granular sludge to convert glucose into hydrogen in two anaerobic fluidized bed reactors (AFBRs) operated at a $\mathrm{pH}$ of 5.5 and $37{ }^{\circ} \mathrm{C}$. The influence of HRT and glucose concentration on hydrogen production in the reactors was examined at a constant organic loading rate of $40 \mathrm{~g}-$ glucose $/ \mathrm{l} / \mathrm{h}$ by varying HRT from 0.125 to $3 \mathrm{~h}$ and glucose concentration from 5 to $120 \mathrm{~g} / \mathrm{l}$. The hydrogen yield obtained in both reactors ranged between 0.4 and $1.7 \mathrm{~mol} \mathrm{H}_{2} / \mathrm{mol}$-glucose, with a maximum yield occurring at an HRT of $0.25 \mathrm{~h}$ and a glucose concentration of $10 \mathrm{~g} / \mathrm{l}$. It was noted that the biofilm had been washed out substantially in the biofilm reactor and the reactor biomass was replaced by granules during the operation of 50 days, and consequently no apparent variation in hydrogen production was observed as the biofilm was replaced by granules. Zhang et al. (2008a) deduced that as compared with the carrier-based biofilm reactor, the granule-based reactor indicated an advantage of better biomass retention without subject to washout of support carriers. Later, Zhang et al. (2008b) equally concluded that a granule-base column-shaped reactor system appears to be the preferred process for continuous hydrogen fermentation on glucose substrate.

Another community reactor optimize for biohydrogen production is the Upflow Anaerobic Sludge Blanket (UASB) and operating conditions of the acidogenic reactor (concentration of solids in the feed, retention time, organic loading density, $\mathrm{pH}$ and flow recirculation) were extensively studied to maximize hydrogen production ( $\mathrm{Yu}$ and $\mathrm{Mu}, 2006$; Zhao et al., 2008). $\mathrm{Mu}$ and $\mathrm{Yu}$ (2007) studied the performance of a granule-based $\mathrm{H}_{2}$-producing upflow anaerobic sludge blanket (UASB) reactor simulated using neural network and genetic algorithm and a model was designed, trained and validated to predict the steady-state performance of the reactor. The $\mathrm{H}_{2}$ concentration, $\mathrm{H}_{2}$ production rate, $\mathrm{H}_{2}$ yield and effluent total organic carbon were the inputs of the model, and the simulation results demonstrate that the model was able to effectively describe the daily variations of the UASB reactor performance, and to predict the steady-state reactor performance at various substrate concentrations and HRTs. The response surface methodology (RSM) was used by Zhao and collaborates (2008) to evaluated the biohydrogen production from sucrose in a granule-based upflow anaerobic sludge in the blanket (UASB) reactor.

Recently, an anaerobic sequencing batch reactor (ASBR), adopted from the classical reactor for wastewater treatment, has shown promising results in hydrogen production by changing the time of each cycle, and the authors concluded that $\mathrm{pH}$ and the cyclic duration of the operations profoundly impacted fermentative hydrogen production (Chen et al., 2009).

Yet another main factor influencing the bacterial productivity and total yield of hydrogen is the partial pressure of produced gas. A novel solution to enhance the bacterial productivity was through reduction of the gas pressure has been proposed by Alshiyab et al. (2009). An increase in the reactor size showed an enhancement in the 
bacterial production of hydrogen. This technique of increasing reactor size resulted to enhance the 1 glucose utilized to maximum yield-hydrogen yield from $269 \mathrm{ml} / \mathrm{g}$ glucose utilized by using $125 \mathrm{ml}$ and 21 reactor size of $448 \mathrm{ml} / \mathrm{g}$, respectively. The hydrogen productivity was also enhanced from $71 \mathrm{ml} / \mathrm{h}$ to a maximum of $91 \mathrm{ml} / \mathrm{h}$. Alshiyab et al. (2009) concluded that by using a bigger reactor size, the effect of gaseous products in fermentation medium was reduced and thereafter enhanced both bacterial productivity and biomass concentration.

\subsection{Novel bacterial strains}

Microbial $\mathrm{H}_{2}$ production is an attractive process accounting for a significant share of the $\mathrm{H}_{2}$ required for the near future. The biochemical hydrogen potential (BHP) tests were conducted to investigate the metabolism of different inoculums fermentation and evaluate the hydrogen potential of bacterial strains species growing on different substrates. Lin et al. (2007) investigate the metabolism of glucose fermentation of four Clostridial species, including C. acetobutylicum M121, C. butyricum ATCC19398, C. tyrobutyricum FYa102, and C. beijerinckii L9 and the results were able to accurately describe the profile of glucose degradation as well as production of biomass, butyrate, acetate, ethanol, and a significant amount of hydrogen gas in the batch tests. Another microbial species, belonging to the genera Enterobacter, Citrobacter, Bacillus, and Clostridium are reported to produce hydrogen through dark fermentation (Nandi and Sengupta, 1998). Apart from pure cultures, various mixed micro-flora and co-cultures have also been explored for hydrogen production from carbohydrates (Das and Verziroglu, 2001). Nevertheless, the search for 'ideal' and more selective microbe(s) for microbial $\mathrm{H}_{2}$ production have thrust the researchers to screen various sources.

Isolating strains that can effectively utilize cellulose materials to produce hydrogen at room temperature is also of great practical interest. Oh et al. (2003b) had isolated a newly isolated Citrobacter sp. Y19 for $\mathrm{CO}-$ dependent $\mathrm{H}_{2}$ production for its capability of fermentative $\mathrm{H}_{2}$ production in batch cultivation. When glucose was used as carbon source, the $\mathrm{pH}$ of the culture medium significantly decreased as fermentation proceeded and $\mathrm{H}_{2}$ production was seriously inhibited but fortifed phosphate at $60-180 \mathrm{mmol} / \mathrm{l}$ alleviated this inhibition. The maximal $\mathrm{H}_{2}$ yield and $\mathrm{H}_{2}$ production rate were estimated to be $2: 49 \mathrm{~mol} \mathrm{H}_{2} / \mathrm{mol}$ glucose and $32: 3 \mathrm{mmol} \mathrm{H}_{2} / \mathrm{g}$ cell/h, respectively. According to Oh et al. (2003b), the overall performance of Y19 in fermentative $\mathrm{H}_{2}$ production was quite similar to that of most $\mathrm{H}_{2}$-producing bacteria previously studied, especially to that of Rhodopseudomonas palustris $\mathrm{P} 4$, and that indicated that the attempt to find an outstanding bacterial strain for fermentative $\mathrm{H}_{2}$ production might be very difficult. In the case glucose present in a medium of Citrobacter Y19 being used for biohydrogen generation, the glucose is believed to serve double roles in enhancing the sustained production rate of hydrogen (Pandey and Pandey, 2008). Firstly, it quenches the free $\mathrm{O}_{2}$ liberated as a side product of reaction catalyzed by nitrogenase, which is $\mathrm{O}_{2}$ labile. Secondly, organic acids produced by this reaction are utilized by the Citrobacter Y19 as organic substrate in anaerobic conditions.

Nevertheless, several other studies followed in this direction and results seemed promising. Wang et al. (2008) isolated a strain $\left(\mathrm{X}_{9}\right)$, a member of clostridia genera (Clostridium acetobutylicum, ATCC 824), from a hydrogen-producing reactor, and determined hydrogen production potential by dark fermentation of this strain from 
microcrystalline cellulose suspensions at $37{ }^{\circ} \mathrm{C}$. In their work, Wang et al. (2008) also tested whether this stain could work with another strain, Ethanoigenens harbinense B49, which could produce hydrogen efficiently from monosaccharides, for bioaugmented biohydrogen production from microcrystalline cellulose. At $37{ }^{\circ} \mathrm{C}$ and $\mathrm{pH} 5.0$, the mono-culture of $\mathrm{X}_{9}$ yielded hydrogen with a 5-h time lag and end liquid products contained primarily of acetate and butyrate. The co-culture of $\mathrm{X}_{9}$ with Ethanoigenens harbinense B49 produced more efficiently the biohydrogen via an ethanol-type fermentation metabolism compared with mono-culture $\mathrm{X}_{9}$ test. It hence meant that the bioaugmentation with $\mathrm{X}_{9}+\mathrm{B} 49$ improved cellulose hydrolysis and the subsequent hydrogen production rates as compared with that of monoculture bioaugmentation with $\mathrm{X}_{9}$. Earlier, Venkata Mohan et al. (2007b) studied the feasibility of a bioaugmentation strategy in the process of enhancing biohydrogen production from chemical wastewater treatment for an OLR of $6.3 \mathrm{kgCOD} / \mathrm{m}^{3} / \mathrm{d}$ in anaerobic sequencing batch biofilm reactor (AnSBBR, Fig. 2) operated at $28{ }^{\circ} \mathrm{C}$ under acidophilic microenvironment $(\mathrm{pH} \mathrm{6)}$ with a total cycle period of $24 \mathrm{~h}$. A parent augmented inoculum, kanamycin resistant, was acquired from an operating upflow anaerobic sludge blanket (UASB) reactor treating chemical wastewater and subjected to selective enrichment by applying repetitive/cyclic pretreatment methods altering between heat-shock treatment at $100^{\circ} \mathrm{C}, 2 \mathrm{~h}$ and acid treatment at $\mathrm{pH} 3,24 \mathrm{~h}$ to eliminate non-spore forming bacteria and to inhibit the growth of methanogenic bacteria. In the case of food waste at upflow anaerobic sludge blanket (UASB) reactor treating wastewater the specific methanogenic activity (SMA) of granule was the highest for butyrate, and the lowest for propionate, also Methanosaeta-like bamboo-shaped rods were present in abundance (Han et al., 2005). From the data obtained, Venkata Mohan et al. (2007b) show a positive influence of the bioaugmentation strategy on the overall $\mathrm{H}_{2}$ production with a specific $\mathrm{H}_{2}$ production almost doubling after augmentation from 0.297 to $0.483 \mathrm{~mol} \mathrm{H}_{2} / \mathrm{kg} \mathrm{COD} / \mathrm{d}$. The survival and retention of the augmented kanamycin resistant inoculum and its positive effect on process enhancement was most seemingly attributable to the adopted reactor configuration and operating conditions. 


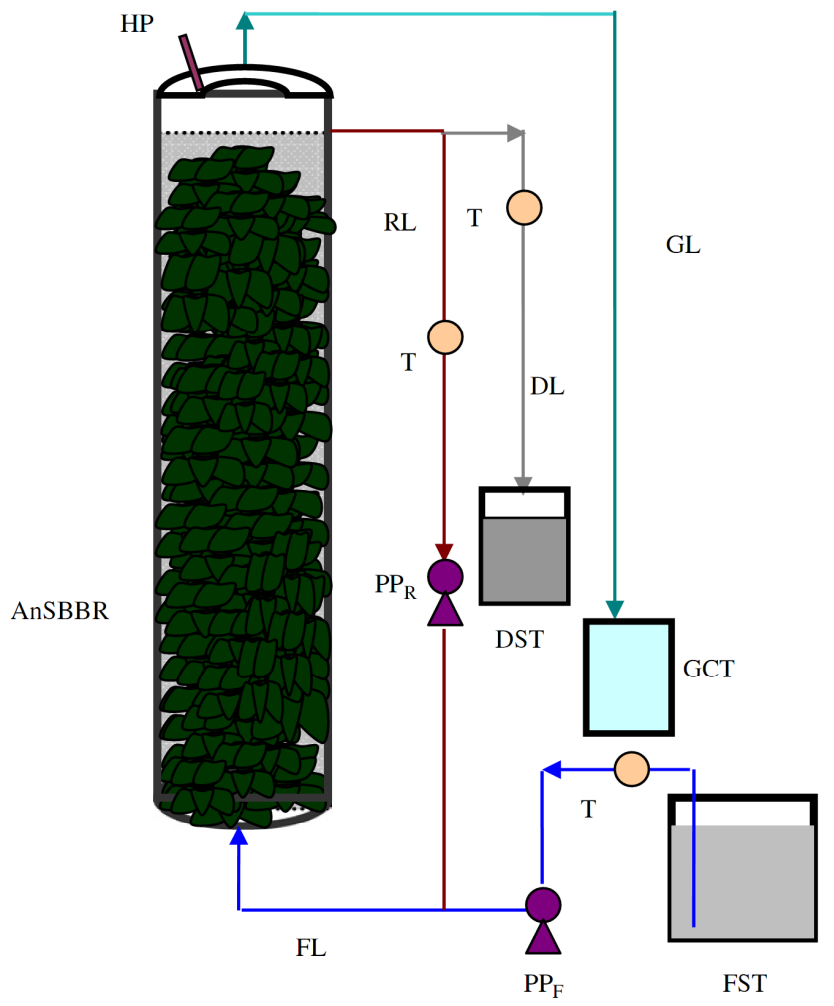

Fig. 2. Schematic details of AnSBBR (HP-hydrogen monitoring probe; PPF-feeding peristaltic pump; PPR-recirculation peristaltic pump; FL-feed line; RL-recirculation line; GL-gas collection line; T-preprogrammed timer; PPD-decanting peristaltic pump; FST-feed storage tank; GCT-gas collection container; DST-decant storage tank). (Venkata Mohan et al., 2007b).

Additionally, analyses of evolution of the microbial community was studied during reactor operation using molecular biology tools (T-RFLP, 16S rRNA cloning library and FISH) and conventional microbiological techniques for examines the feasibility of producing hydrogen by dark fermentation (Castelló et al., 2009). The results showed that hydrogen can be produced but in low amounts and microbiological studies showed the prevalence of fermentative organisms from the genera Megasphaera, Anaerotruncus, Pectinatus and Lactobacillus, which may be responsible for hydrogen production. According Venkata Mohan and collaborates (2007b), the images analyses made on the scanning electron microscope (SEM) confirmed the selective enrichment of morphologically similar group of bacteria capable of producing $\mathrm{H}_{2}$ under acidophilic conditions in anaerobic microenvironment. The survival and maintenance of the augmented consortia suggested that the growth rate of the organism might have been higher than washout and the activity of the grazers was negligible. The SEM images $(\mathrm{X} 5 \mathrm{~K})$ of augmented mixed consortia showed slightly bent, rod-shaped and thick fluorescent capsid bacteria (Fig. 3). It was most apparently presumed from the image visibility that the adopted selective enrichment procedure might have resulted in an enrichment of morphologically similar group of rod-shaped bacteria capable of producing $\mathrm{H}_{2}$. 

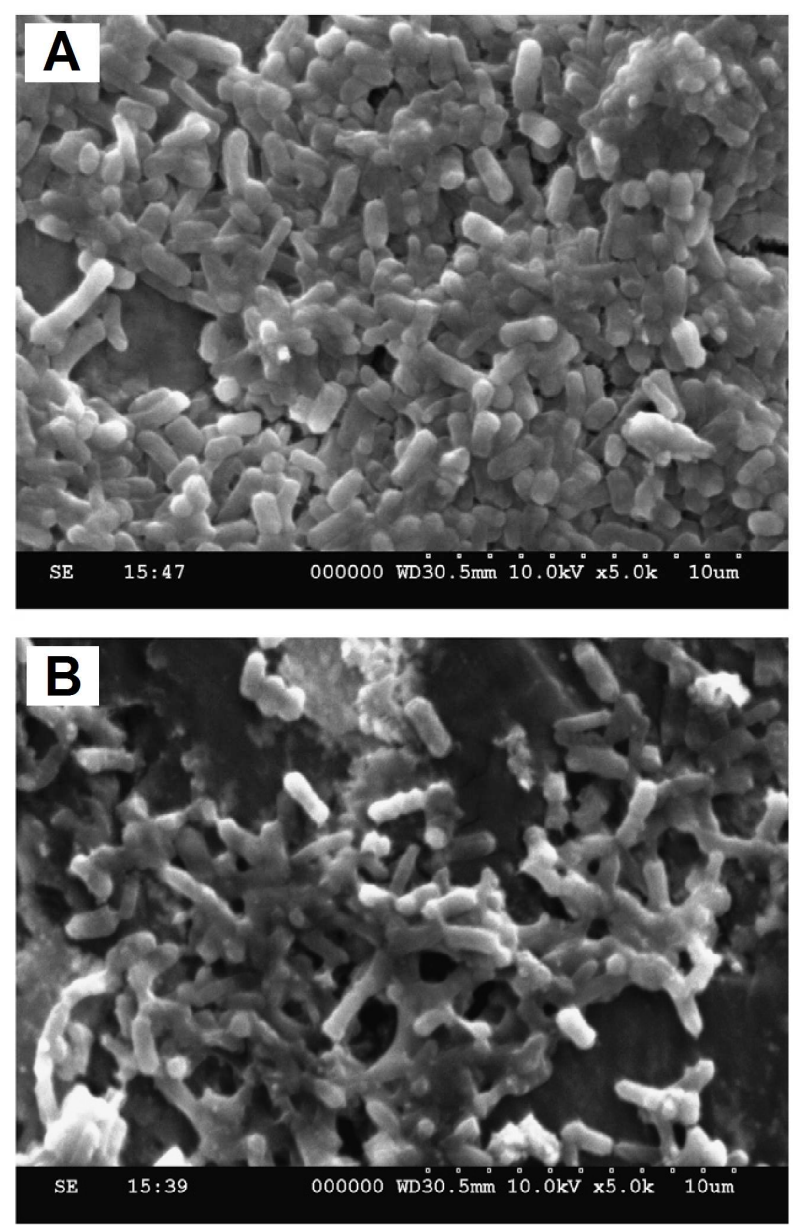

Fig. 3. Scanning electron microscopy (SEM) images (X5 K): (a) Selectively enriched kanamycin resistant anaerobic mixed culture (bioaugmented culture). (b) Biofilm taken after five cycles of feeding after bioaugmentation. (Venkata Mohan et al., 2007b).

\subsection{Genetic manipulations}

Improved biohydrogen production rates will clearly benefit from both the selection of a suitable phototroph and the engineering of its biochemical pathways (Kruse et al., 2005). The majority of microorganisms currently studied for hydrogen photoproduction have been selected because of their ease of cultivation, which is often consistent with slow growth rates (Kruse et al., 2005). However, further efforts to overcome existing issues of low rates and yields of biohydrogen production in optimized reactors configurations will need to rely on the ability to analyze, predict and engineer microbial metabolism in native $\mathrm{H}_{2}$-producing strains as well as genetically engineerable strains with constructed $\mathrm{H}_{2}-$ metabolism (Vignais et al., 2006; Jones, 2008).

Recently, there has been substantial progress in identifying relevant bioenergy genes and pathways in microalgae, and powerful genetic manipulations have been developed to engineer some strains via the targeted disruption of endogenous genes and/or transgene expression (Beer et al., 2009). Collectively, the progress that has been realized in these areas is rapidly advancing the ability of researchers and engineers to genetically optimize the production of targeted biofuels including biohydrogen. Akhtar 
and Jones (2008) have recently engineered a synthetic hydF-hydE-hydG-hydA operon for biohydrogen production while Xing et al. (2008) reported genomic evidence for the presence of novel $\mathrm{H}_{2}$-producing bacteria in acidophilic ethanol- $\mathrm{H}_{2}$-coproducing communities that were enriched using molasses wastewater. Earlier, Melis et al. (2007) have examined the physiological and genetic engineering approaches by which to improve the hydrogen metabolism characteristics of microalgae. Melis et al. (2007) discussed the application of sulphur-nutrient deprivation to attenuate $\mathrm{O}_{2}$-evolution and to promote $\mathrm{H}_{2}$-production, as well as the genetic engineering of sulphate uptake through manipulation of a newly reported sulphate permease in the chloroplast of the model green alga Chlamydomonas reinhardtii.

Franchi et al. (2004) have constructed three differently metabolically engineered strains, 2 single $\mathrm{PHA}^{-}$and $\mathrm{Hup}^{-}$mutants and one double $\mathrm{PHA}^{-} / \mathrm{Hup}^{-}$mutant, of the purple nonsulphur photosynthetic bacterium Rhodobacter sphaeroides RV, were constructed to improve a light-driven biohydrogen production process combined with the disposal of solid food wastes. These phenotypes were designed to abolish, singly or in combination, the competition of $\mathrm{H}_{2}$ photoproduction with polyhydroxyalkanoate (PHA) accumulation by inactivating PHA synthase activity, and with $\mathrm{H}_{2}$ recycling by abolishing the uptake hydrogenase enzyme. With lactic acid-based synthetic medium, the single $\mathrm{Hup}^{-}$and the double $\mathrm{PHA}^{-} / \mathrm{Hup}^{-}$mutants, but not the single $\mathrm{PHA}^{-}$mutant, exhibited increased rates of $\mathrm{H}_{2}$ photoproduction, about one third higher than that of the wild-type strain. All three mutants sustained a longer-term $\mathrm{H}_{2}$ photoproduction phase than the wild-type strain, with the double mutant exhibiting overall the largest amount of $\mathrm{H}_{2}$ evolved. The work of Franchi et al. (2004) hence demonstrated the feasibility of single and multiple gene engineering of microorganisms to redirect their metabolism for improving $\mathrm{H}_{2}$ photoproduction using actual waste-derived substrates. Yet another interesting advance was made by Yoshino et al. (2007) where a strategy to establish cyanobacterial strains with high levels of $\mathrm{H}_{2}$ production that involved the identification of promising wild-type strains followed by optimization of the selected strains using genetic engineering was developed. Yoshino et al. (2007) selected the Nostoc sp. PCC by virtue of it having the highest nitrogenase activity. After sequencing the uptake hydrogenase (Hup) gene cluster as well as the bidirectional hydrogenase gene cluster from the strain, and constructing a mutant $(\Delta h u p L)$ by insertional disruption of the hupL gene, $\mathrm{H}_{2}$ was produced a rate three times that of the wild-type. Lately, Kars et al. (2008) improved the hydrogen producing capacity of cells by introducing a suicide vector containing a gentamicin cassette in the hupSL genes into Rhodobacter sphaeroiodes O.U.001. The wild-type and the mutant cells showed similar growth patterns but the total volume of hydrogen gas evolved by the mutant was $20 \%$ higher than that of the wild type strain.

$\mathrm{NH}_{4}{ }^{+}$is typically an inhibitor to hydrogen production from organic wastewater by photo-bacteria. Recently, Zheng et al. (2009) found the biohydrogen generation with wild-type anoxygenic phototrophic bacterium Rhodobacter sphaeroides was to be sensitive to $\mathrm{NH}_{4}{ }^{+}$due to the significant inhibition of $\mathrm{NH}_{4}{ }^{+}$to its nitrogenase. In order to avoid the inhibition of $\mathrm{NH}_{4}{ }^{+}$to biohydrogen generation by $R$. sphaeroides, a glutamine auxotrophic mutant $R$. sphaeroides AR-3 was obtained by mutagenizing with ethyl methane sulphonate. Zheng et al. (2009) noticed that the AR-3 mutant could generate biohydrogen efficiently in the hydrogen production medium with a higher $\mathrm{NH}_{4}^{+}$ concentration, because the inhibition of $\mathrm{NH}_{4}{ }^{+}$to nitrogenase of AR-3 was released. 
Under suitable conditions, Zheng et al. (2009) successfully demonstrated that AR-3 could effectively produce biohydrogen from tofu wastewater, which normally contained 50-60 mg/l NH${ }_{4}{ }^{+}$, with an average generation rate of $14.2 \mathrm{ml} / \mathrm{l} / \mathrm{h}$. The salient improvement was that the biohydrogen generation rate had more than doubled compared with that from wild-type $R$. sphaeroides. Several other related studies hence indicate that genetic, and hence metabolic, engineering (Vignais et al., 2006; Mathews and Wang, 2009) is a promising approach to the improvement of biological hydrogen production by existing microorganisms, particularly as concerns the redirection and optimization of the flow of reducing equivalents to the $\mathrm{H}_{2}$-producing enzymes, nitrogenase or hydrogenase.

\section{Conclusion}

Day by day the human society seems to have an unquenchable appetite for energy to meet up with global prosperity. But yet paradoxically dependence on fossil fuels as the primary energy source appears to be a major cause to global warming, environmental degradation and health problems which threaten the survival of mankind. Hydrogen from both fossil and renewable biomass resources is a sustainable source of energy not limited and with different applications. The biological production of hydrogen (Biohydrogen) has attracted worldwide attention and enjoys much promise as a green fuel owing to the fact that hydrogen can be produced from renewable organic matters. The several methods and experimental techniques/technologies so far developed and analyzed offer promising potential for practical and/or industrial application, for become commercially competitive should it be able to synthesize sufficient hydrogen. Additionally, also the use of modern bioreactors and specific substrates (food crops and lignocellulosic wastes) will be economically and environmentally less costly and inherent to the biohydrogen energy promise. Biohydrogen production from the fermentation of renewable substrates is one promising alternative, when one considers that the organic substrates (agriculture, crop residues, the food industry and market waste, animal waste and organic matter of municipal solid waste) are present in very large quantities as subproducts or waste and can be readily utilized for biohydrogen production.

The most commonly used technologies of biohydrogen production include direct and indirect biophotolysis, photo-fermentations, and dark-fermentation. This biohydrogen production technologies are still in a very early stage of their research and development (R\&D); and further applied R\&D aimed at enhancing the rates of biosynthesis and final yields of hydrogen are essential prerequisites to optimize in a first instance. Optimization of bioreactor designs and operational conditions for $\mathrm{pH}$ and microbial flora, testing and validation of biological, chemical and physical pretreatments, rapid removal and purification of gases, and genetic modifications of enzymatic metabolic pathways that compete with hydrogen producing enzyme systems offer exciting prospects for biohydrogen systems.

The specific areas of research can be summarized as searching for, reengineering and improving photosynthetic microorganisms which have a high hydrogen production capacity; large scale cultivation techniques for maximizing and making more cost-effective the efficiency of hydrogen production making use of such microorganisms; development of techniques for effectively separating and refining the 
hydrogen formed.; design of integrated systems for biohydrogen production followed by technical evaluations and cost-benefit analyses. The biological production of hydrogen (Biohydrogen) on an industrial scale attracts worldwide attention and enjoys much promise as a green fuel to the growing global energy demand from an environmental sustainability perspective (renewable organic matters).

Finally, it is clear that global tools such as the LCA and the comparison with established processes are necessary to discern among the possibilities of biohydrogen production and to compare with other sources of energy.

\section{References}

1. Akhtar, M.K., Jones, P.R., 2008. Engineering of a synthetic hydF-hydE-hydG-hydA operon for biohydrogen production. Anal. Biochem. 373, 170-172.

2. Akkerman, I., Janssen, M., Rocha, J., Wijffels, R.H., 2002. Photobiological hydrogen production: photochemical efficiency and bioreactor design. Int. J. Hydrogen Energy 27, 1195-1208.

3. Allahverdiyeva, Y., Leino, H., Saari, L., Fewer, D.P., Shunmugam, S., Sivonen, K., Antonopoulou, G., Gavala, H.N., Skiadas, I.V., Angelopoulos, K., Lyberatos, G., 2008. Biofuels generation from sweet sorghum: Fermentative hydrogen production and anaerobic digestion of the remaining biomass. Bioresource Technol. 99, 110-119.

4. Anastas, P.T., Warner, J.C., 1998. Green Chemistry, Theory and Practice, Oxford University Press.

5. Anastas, P.T., Kirchhoff, M.M., 2002. Origins, Current status, and future challenges of Green Chemistry. Acc. Chem. Res. 35, 686-694.

6. Anastas, P.T., Zimmerman, J.B., 2003. Design through the 12 Principles of Green Engineering. Environ. Sci. Technol. 37, 94-101.

7. Anastas, P.T., Lankey, R.L., 2000. Life-Cycle Assessment and Green Chemistry: The Yin and Yang of Industrial Ecology. Green Chem. 6, 289-295.

8. Antonopoulou, G., Ntaikou, I., Gavala, H.N., Skiadas, I.V., Angelopoulos, K., Lyberatos, G., 2007. Biohydrogen production from sweet sorghum biomass using mixed acidogenic cultures and pure cultures of Ruminococcus Albus. Global NEST J. 9, 144-151.

9. Alshiyab, H.S., Kalil, M.S., Hamid, A.A., Yusoff, W.M.W., 2009. Improvement of biohydrogen production under increased the reactor size by $C$. acetobutylicum NCIMB 13357. American J. Environ. Sci. 5, 33-40.

10. Aro, E. -M., 2010. Screening for biohydrogen production by cyanobacteria isolated from the Baltic Sea and Finnish lakes. Int. J. Hydrogen Energy 35, 1117-1127.

11. Asada, Y., Miyake, J., 1999. Photobiological hydrogen production. J. Biosci. Bioeng. 88, 1-6.

12. Beer, L.L., Boyd, E.S., Peters, J.W., Posewitz, M.C., 2009. Engineering algae for biohydrogen and biofuel production. Curr. Opin. Biotechnol. 20, 264-271.

13. Benemann, J., 1996. Hydrogen biotechnology: progress and prospects. Nat. Biotechnol. 14, 1101-1103.

14. Bouallagui, H., Torrijos, M., Godon, J.J., Moletta, R., Ben Cheikh, R., Touhami, Y., Delgenes, J.P., Hamdi, M., 2004. Two-phases anaerobic digestion of fruit and vegetable wastes: bioreactors performance. Biochem. Eng. J., 21:193-197. 
15. Cai, M., Liu, J., Wei, Y., 2004. Enhanced biohydrogen production from sewage sludge with alkaline pretreatment. Environ. Sci. Technol. 38, 3195-3202.

16. Castelló, E., García y Santos, C., Iglesias, T., Paolino, G., Wenzel, J., Borzacconi, L., Etchebehere, C. 2009. Feasibility of biohydrogen production from cheese whey using a UASB reactor: Links between microbial community and reactor performance. Int. J. Hydrogen Energy, 34, 5674-5682.

17. Chang, J.-S., Lee, K.-S., Lin, P.-J., 2002. Biohydrogen production with fixed-bed bioreactors. Int. J. Hydrogen Energy 27, 1167-1174.

18. Chang, J.S., Yang, S.M., 2006. Application of artificial neural networks coupled with sequential pseudo-uniform design to optimization of membrane reactors for hydrogen production. J. Chin. Inst. Chem. Eng. 37, 395-400.

19. Chang, F.Y., Lin, C.Y., 2004. Biohydrogen production using an up-flow anaerobic sludge blanket reactor. Int. J. Hydrogen Energy 29, 33-39.

20. Chen, C.C., Lin, C.Y., 2003. Using sucrose as a substrate in an anaerobic hydrogen-producing reactor. Adv. Environ. Res. 7, 695-699.

21. Clark, J.H., 2006. Green chemistry: today (and tomorrow). Green Chem. 8, 17-21.

22. Carrieria, D., Ananyeva, G., Amaya, M., Garcia Costas, Bryant, D.A., Dismukesa, C., 2008. Renewable hydrogen production by cyanobacteria: Nickel requirements for optimal hydrogenase activity. Int. J. Hydrogen Energy, 33, 2014-2022.

23. Das, D., 2009. Advances in biohydrogen production processes: An approach towards commercialization. Int. J. Hydrogen Energy 34, 7349-7357.

24. Das, D., Veziroglu, T.N., 2001. Hydrogen production by biological processes: a survey of literature. Int. J. Hydrogen Energy 26, 13-28.

25. Davila-Vazquez, G., Cota-Navarro, C.B., Rosales-Colunga, L.M., de LeónRodríguez, A., Razo-Flores, E., 2009. Continuous biohydrogen production using cheese whey: Improving the hydrogen production rate. Int. J. Hydrogen Energy 34, 4296-4304.

26. Dinsdale, R.M., Freda R. Hawkes, Dennis L. 1997. Hawkes Mesophilic and thermophilic anaerobic digestion with thermophilic pre-acidification of instant-coffee-production wastewater. Water Res., 31, 1931-1938.

27. Fan, Y., Lia, C., Lay, J.J., Houa, H., Zhanga, G. 2004. Optimization of initial substrate and $\mathrm{pH}$ levels for germination of sporing hydrogen-producing anaerobes in cow dung compost. Bioresource Technology, 91, 189-193

28. Fan, K.S., Kan, N.R., Lay, J.J., 2006. Effect of hydraulic retention time on anaerobic hydrogenesis in CSTR. Bioresource Technol. 97, 84-89.

29. Fang, H.H.P., Liu, H., Zhang, T., 2005. Phototrophic hydrogen production from acetate and butyrate in wastewater. Int. J. Hydrogen Energy 30, 785-793.

30. Fang, H.H.P., Liu, H., 2002. Effect of $\mathrm{pH}$ on hydrogen production from glucose by a mixed culture. Bioresource Technol. 82, 87-89.

31. Forster-Carneiro, T., Pérez, M., Romero, L.I., 2008. Anaerobic digestion of different municipal solid wastes: dry thermophilic performance. Bioresource Technol., 99, 8180-8184.

32. Franchi, E., Tosi, C., Scolla, G., Penna, G.D., Rodriguez, F., Pedroni, P.M., 2004. Metabolically engineered Rhodobacter sphaeroides RV strains for improved biohydrogen photoproduction combined with disposal of food wastes. Mar. Biotechnol. 6, 552-565. 
33. Gadhamshetty, V., Arudchelvam, Y., Nirmalakhandan, N., Johnson, D., 2010. Modeling dark fermentation for biohydrogen production: ADM1-based model vs. Gompertz model. Int. J. Hydrogen Energy 35, 479-490.

34. Gadhamshetty, V., Sukumaran, A., Nirmalakhandan, N., Myint, M.T., 2008. Photofermentation of malate for biohydrogen production- A modeling approach. Int. J. Hydrogen Energy 33, 2138-2146.

35. Ghirardi, M.L,, Zhang, L., Lee, J.W., Flynn, T., Seibert, M., Greenbaum, E., Melis, A., 2000. Microalgae: a green source of renewable $\mathrm{H}_{2}$. Tibtech 18, 506-511.

36. Guo, L., Li, X.-M., Bo, X., Yang, Q., Zeng, G.-X., Liao, D., Liu, J.-J., 2008. Impacts of sterilization, microwave and ultrasonication pretreatment on hydrogen producing using waste sludge. Bioresource. Technol. 99, 36513658.

37. Hallenbeck, P.C., Benemann, J.R., 2002. Biological hydrogen production: fundamentals and limiting processes. Int. J. Hydrogen Energy 27, 1185-1193.

38. Han, S-K., Kim, S-Y., Shin, H-S., 2005. UASB treatment of wastewater with VFA and alcohol generated during hydrogen fermentation of food waste. Process Biochem., 40, 2897-2905.

39. Han, S.-K., Shin, H.-S., 2004. Biohydrogen production by anaerobic fermentation of food waste. Int. J. Hydrogen Energy 24, 569-577.

40. Hawkes, F.R., Dinsdale, R., Hawkes, D.L., Hussy, I., 2002. Sustainable fermentative hydrogen production: challenges for process optimization. Int. J. Hydrogen Energy 27, 1339-1347.

41. Höfer, R., Bigorra, J., 2007. Green chemistry - A sustainable solution for industrial specialties applications. Green Chem., 203-212.

42. Holladay, J.D., Hu, J., Kinga, D.L., Wanga, Y., 2009. An overview of hydrogen production technologies. Catal. Today, 139: 244-260

43. Jo, J.H., Lee, D.S., Park, J.M., 2008. The effects of pH on carbon material and energy balances in hydrogen-producing Clostridium tyrobutyricum JM1. Bioresource Technol. 99, 8485-8491.

44. Jones, P.R., 2008. Improving fermentative biomass-derived $\mathrm{H}_{2}$-production by engineering microbial metabolism. Int. J. Hydrogen Energy 33, 5122-5130.

45. Kapdan, I.K., Kargi, F., 2006. Bio-hydrogen production from waste materials. Enzyme Microb. Technol. 38, 569-582.

46. Kars, G., Gündüz, U., Rakhely, G., Yücel, M., Eroğlu, İ., Kovacs, K.L., 2008. Improved hydrogen production by uptake hydrogenase deficient mutant strain of Rhodobacter sphaeroides O.U.001. Int. J. Hydrogen Energy 33, 3056-3060.

47. Kidwai, M., Mohan, R., 2005. Green Chemistry: An innovative technology. Foundations Chem. 7, 269-287.

48. Kim, S.H., Han, S.K., Shin, H.S., 2004. Feasibility of biohydrogen production by anaerobic co-digestion of food waste and sewage sludge. Int. J. Hydrogen Energy 29, 1607-1616.

49. Kirchhoff, M.M., 2003. Promoting green engineering through green chemistry. Environ. Sci. Technol. 37, 5349-5353.

50. Kotay, S.M., Das, D., 2009. Novel dark fermentation involving bioaugmentation with constructed bacterial consortium for enhanced biohydrogen production from pretreated sewage sludge. Int. J. Hydrogen Energy 34, 7489-7496.

51. Kotay, S.M., Das, D., 2008. Biohydrogen as a renewable energy resourceProspects and potentials. Int. J. Hydrogen Energy 33, 258-263. 
52. Kotsopoulos, T.A., Zeng, R.J., Angelidaki, I., 2006. Biohydrogen production in granular up-flow anaerobic sludge blanket (UASB) reactors with mixed cultures under hyper-thermophilic temperature $\left(70^{\circ} \mathrm{C}\right)$. Biotechnol. Bioeng., 94 , 296-302.

53. Kovács, K.L., Maróti, G., Rákhely, G., 2006. A novel approach for biohydrogen production. Int. J. Hydrogen Energy 31, 1460-1468.

54. Kruse,O., Rupprecht, J., Mussgnug, J.H., Dismukes, G.C., Hankamer, B., 2005. Photosynthesis: a blueprint for solar energy capture and biohydrogen production technologies. Photochem. Photobiol. Sci. 4, 957-969.

55. Kumar, P., Satyanarayana, T., 2007. Optimization of culture variables for improving glucoamylase production by alginate-entrapped Thermomисоr indicae-seudaticae using statistical methods. Bioresource Technol. 98, 12521259.

56. Kurokawa, T., Tanisho, S., 2005. Effects of formate on fermentative hydrogen production by Enterobacter aerogenes. Mar. Biotechnol. 7, 112-118

57. Kyazze, G., Martínez-Pérez, N., Dinsdale, R., Premier, G.C., Hawkes, F.R., Guwy, A.J., Hawkes, D.L., 2005. Influence of substrate concentration on the stability and yield of continuous biohydrogen production. Biotechnol. Bioeng., 93, 971-979.

58. Lankey, R.L., Anastas, P.T., 2002. Life-cycle approaches for assessing green chemistry technologies. Ind. Eng. Chem. Res. 41, 4498-4502.

59. Lay, J., Fan, K.S., Chang, J., Ku, C.H., 2003. Influence of chemical nature of organic wastes on their conversion to hydrogen by heat-shock digested sludge. Int. J. Hydrogen Energy, 28, 1361-1367.

60. Lay, J.J., 2001. Biohydrogen generation by mesophilic anaerobic fermentation of microcrystalline cellulose. Biotechnol. Bioeng. 74, 280-287.

61. Lay, J.J., Lee, Y.J., Noike, T., 1999. Feasibility of biological hydrogen production from organic fraction of municipal solid waste. Water Res. 33, 2579-2586.

62. Lee, K.S., Wu, J.F., Lo, Y.S., Lo, Y.C., Lin, P.J., Chang, J.S., 2004. Anaerobic hydrogen production with an efficient carrier-induced granular sludge bed bioreactor. Biotechnol. Bioeng., 87, 648-657.

63. Lee, K.-S., Lo, Y.-C., Lin, P.-J., Chang, J.-S., 2006. Improving biohydrogen production in a carrier-induced granular sludge bed by altering physical configuration and agitation pattern of the bioreactor. Int. J. Hydrogen Energy 31, 1648-1657.

64. Levin, D.B., Pitt, L., Love, M., 2004. Biohydrogen production: prospects and limitations to practical application. Int. J. Hydrogen Energy 29, 173-185.

65. Li, S-L., Whang, L-M., Chao, Y-C., Wang, Y-H., Wang, Y-F., Hsiao, C.J, Tseng, I-C., Bai, M-D., Cheng, S-S., 2010. Effects of hydraulic retention time on anaerobic hydrogenation performance and microbial ecology of bioreactors fed with glucose-peptone and starch-peptone. Int. J. Hydrogen Energy, 35, 61-70.

66. Li, Z., Wang, H., Tang, Z., Wang, X., Bai, J., 2008. Effects of pH value and substrate concentration on hydrogen production from the anaerobic fermentation of glucose. Int. J. Hydrogen Energy 13, 1-6.

67. Li, Y.Y., Noike, T., 1992. Upgrading of anaerobic digestion of waste activated sludge by thermal pretreatment.Water Sci. Technol. 26, 857-866.

68. Lin, C.Y., Jo, C.H., 2003. Hydrogen production from sucrose using an anaerobic sequencing batch reactor process. J. Chem. Technol. Biotechnol, 78, 678-684. 
69. Lin, P-Y., Whang, L-M., Wu, Y-R., Ren, W-J., Hsiao, C-J., Li, S-L., Chang, J-S., 2007. Biological hydrogen production of the genus Clostridium: Metabolic study and mathematical model simulation. Int. J. Hydrogen Energy, 32, $1728-1735$.

70. Liu, H., Zhang, T., Fang, H.H.P., 2003. Thermophilic $\mathrm{H}_{2}$ production from a cellulose-containing wastewater. Biotechnol. Lett. 25, 365-369.

71. Logan, B.E., 2010. Scaling up microbial fuel cells and other bioelectrochemical systems. Appl. Microbiol. Biotechnol. 85, 1665-1671.

72. Logan, B.E., 2004. Biologically extracting energy from wastewater: biohydrogen production and microbial fuel cells. Environ. Sci. Technol. 38, 160A-167A.

73. Logan, B.E., Oh, S.E., Kim, I.S., Van Ginkel, S., 2002. Biological hydrogen production: measured in batch anaerobic respirometers. Environ. Sci. Technol. $36,2530-2535$.

74. Lou, J., Dawson, K.A., Strobel, H.J., 1997. Cellobiose and cellodextrin metabolism by the ruminal bacterium Ruminococcus albus. Curr. Microbiol. 35, 221-227.

75. Maag, G., Zanganeh, G., Steinfeld. A., 2009. Solar thermal cracking of methane in a particle-flow reactor for the co-production of hydrogen and carbon. Int. J. Hydrogen Energy 34, 7676-7685.

76. Manish, S., Banerjee, R., 2008. Comparison of biohydrogen production processes. Int. J. Hydrogen Energy 33, 279-286.

77. Mathews, J. and Wang, G., 2009. Metabolic pathway engineering for enhanced biohydrogen production. Int. J. Hydrogen Energy 34, 7404-7416.

78. Melis, A., Seibert, M., Ghirardi, M.L., 2007. Hydrogen fuel production by transgenic microalgae. Transgenic Microalgae as Green Cell Factories, Springer, New York, pp. 110-121.

79. Miyake, J., Miyake, M., Asada, Y., 1999. Biotechnological hydrogen production: research for efficient light energy conversion. J. Biotechnol. 70, 89-101.

80. Mohanakrishna, G., Kannaiah Goud, R., Venkata Mohan, S., Sarma, P.N., 2010. Enhancing biohydrogen production through sewage supplementation of composite vegetable based market waste. Int. J. Hydrogen Energy 35, 533-541.

81. Mu, Y., Zheng, X-J., Yu., H-Q., 2009. Determining optimum conditions for hydrogen production from glucose by an anaerobic culture using response surface methodology (RSM). Int. J. Hydrogen Energy, 34, 7959-7963.

82. $\mathrm{Mu}, \mathrm{Y}$., Yu, H-Q., 2007. Simulation of biological hydrogen production in a UASB reactor using neural network and genetic algorithm. Int. J. Hydrogen Energy, 32, 3308-3314.

83. Mu, Y.,. Wang, G., Yu, H.-Q., 2006. Response surface methodological analysis on biohydrogen production by enriched anaerobic cultures. Enzyme Microb. Technol. 38, 905-913.

84. Nandi, R., Sengupta, S., 1998. Microbial production of hydrogen: An overview. Crit. Rev. Microbiol. 24, 61-84.

85. Nandi, R., Sengupta, S., 1998. Microbial production of hydrogen: An overview. Crit. Rev. Microb. 24, 61-84.

86. Oh, S.-E., Van Ginkel, S., Logan, B.E., 2003a. The relative effectiveness of pH control and heat treatment for enhancing biohydrogen gas production. Environ. Sci. Technol. 37, 5186-5190.

87. Oh, Y.-K., Seol, E.-H., Kim, J.R., Park, S., 2003b. Fermentative biohydrogen production by a new chemoheterotrophic bacterium Citrobacter sp. Y19. Int. J. Hydrogen Energy 28, 1353-1359. 
88. Okamoto, M., Miyahara, T., Mizuno, O., Noike, T., 2000. Biological hydrogen potential of materials characteristic of the organic fraction of municipal solid wastes. Water Sci. Technol. 41, 25-32.

89. O-Thong, S., Prasertsan, P., Intrasungkha, Dhamwichukorn, S., Birkeland, N.K., 2007. Improvement of biohydrogen production and treatment efficiency on palm oil mill effluent with nutrient supplementation at thermophilic condition using an anaerobic sequencing batch reactor. Enzyme Microb. Technol. 41, 583-590.

90. Palazzi, E., Fabiano, B., Perego, P., 2000. Process development of continuous hydrogen production by Enterobacter aerogenes in a packed column reactor. Bioprocess Eng. 22, 205-213.

91. Pandey, A., Pandey, A., 2008. Reverse micelles as suitable microreactor for increased biohydrogen production. Int. J. Hydrogen Energy 33, 273-278.

92. Pattra, S., Sangyoka, S., Boonmee, M., Reungsang, A., 2008. Bio-hydrogen production from the fermentation of sugarcane bagasse hydrolysate by Clostridium butyricum. Int. J. Hydrogen Energy 33, 5256-5265.

93. Penaud, V., Delgenès, J.P., Moletta, R., 1999. Thermo-chemical pretreatment of a microbial biomass: influence of sodium hydroxide addition on solubilization and anaerobic biodegradability. Enzyme Microb. Technol. 25, 258-263.

94. Rachman, M.A., Nakashimada, Y., Kakizono, T., Nishio, N., 1998. Hydrogen production with high yield and high evolution rate by self-flocculated cells of Enterobacter aerogenes in a packed-bed reactor. Appl. Microbiol. Biotechnol. 49, 450-454.

95. Ran, N., Zhao, L., Chen, Z., Tao, J., 2008. Recent applications of biocatalysis in developing green chemistry for chemical synthesis at the industrial scale. Green Chem. 10, 361-372.

96. Raposo, F., Borja, R., Sánchez, E., Martín, M.A., Martín, A., 2004. Performance and kinetic evaluation of the anaerobic digestion of two-phase olive mill effluents in reactors with suspended and immobilized biomass. Water Res., 38, 2017-2026.

97. Refaat, A.A., El Sheltawy, S.T., 2008. Biohydrogen production by Clostridium beijerinckii. WIT Trans. Ecol. Environ. 1, 123-132.

98. Li, D., Chen, H., 2007. Biological hydrogen production from steam-exploded straw by simultaneous saccharification and fermentation. Int. J. Hydrogen Energy 32, 1742-1748.

99. Reith, J.H., Wijffels, R.H., Barten, H., 2003. Bio-methane \& Bio-hydrogen. Status and perspectives of biological methane and hydrogen production. Dutch Biological Hydrogen Foundation. Wageningen, pp.103-123.

100. Ren, N.Q., Chua, H., Chan, S.Y., Tsang, Y.F., Wang, Y.J., Sin, N., 2007. Assessing optimal fermentation type for bio-hydrogen production in continuous-flow acidogenic reactors. Bioresource Technol. 98, 1774-1780.

101. Ruknongsaeng, P., Reungsang, A., Moonamart, S., Danvirutai, P., 2005. Influent of nitrogen, acetate and propionate on hydrogen production from pineapple waste extract by Rhodospirillum rubrum. J. Water Environ. Technol. 13, 93-117.

102. Sangyoka, S., Reungsang, A., Moonamart, S., 2007. Repeated-batch fermentative for biohydrogen production from cassava starch manufacturing wastewater. Pakistan J. Biol. Sci. 10, 1782-1789. 
103. Shin, J.-H., Yoon, J.H., Lee, S.J., Park, J.T., 2010. Hydrogen production from formic acid in $\mathrm{pH}$-stat fed-batch operation for direct supply to fuel cell. Bioresource Technol. 101, S53-S58.

104. Shin, J.-H., Yoon, J.H., Sim, S.J., Kim, M.S., Park, T.H., 2007. Fermentative hydrogen production by the newly isolated Enterobacter asburiae SNU-1. Int. J. Hydrogen Energy 32, 192-199.

105. Sparling, R., Risbey, D., Poggi-Varaldo, H.M., 1996. Hydrogen production from inhibited anaerobic composters. Int. J. Hydrogen Energy, 22:563-566.

106. Taguchi, F., Yamada, K., Hasegawa, K., Takisaito, T., Hara, K., 1996. Continuous hydrogen production by Clostridium sp. Strain No. 2 from cellulose hydrolysate in aqueous two phase system. J. Ferment. Bioeng. 82, 80-83.

107. Tang, S.Y., Bourne, R.A., Smith, R.L., Poliakoff, M., 2008. The 24 Principles of Green Engineering and Green Chemistry: "IMPROVEMENTS PRODUCTIVELY”. Green Chem. 10, 268-269.

108. Tundo, P., Anastas, P., StC. Black, D., Breen, J., Collins, T., Memoli, S., Miyamoto, J., Polyakoff, M., Tumas, W., 2000. Synthetic pathways and processes in green chemistry. Introductory overview. Pure Appl. Chem. 72, 1207-1228.

109. Ueno, Y., Sasaki, D., Fukui, H., Haruta, M. ,Ishii, M., Igarashi, Y., 2006. Changes in bacterial community during fermentative hydrogen and acid production from organic waste by thermophilic anaerobic microflora. J. Appl. Microbiol., 101, 331-343.

110. Van Ginkel, S.W., Oh, S.E., Logan, B.E., 2005. Biohydrogen gas production from food processing and domestic wastewaters. Int. J. Hydrogen Energy 30, $1535-1542$.

111. Van Ginkel, S.W., Lay, J.J., Sung, S., 2001. Biohydrogen production as a function of $\mathrm{pH}$ and substrate concentration. Environ. Sci. Technol. 35, 47194725.

112. Venkata Mohan, S., 2010. Waste to renewable energy: A sustainable and green approach towards production of biohydrogen by acidogenic fermentation. Sustainable Biotechnology, Springer Netherlands, pp. 129-164.

113. Venkata Mohan, S., Lalit Babu, V., Sarma, P.N., 2008. Effect of various pretreatment methods on anaerobic mixed microflora to enhance biohydrogen production utilizing dairy wastewater as substrate. Bioresource Technol. 99, 59-67.

114. Venkata Mohan, S., Lalit Babu, V., Sarma, P.N., 2007a. Anaerobic biohydrogen production from dairy wastewater treatment in sequencing batch reactor (AnSBR): Effect of organic loading rate. Enzyme Microb. Technol. 41, 506515.

115. Venkata Mohan, S., Mohanakrishna, G., Veer Raghavulu, S., Sarma, P.N., 2007b. Enhancing biohydrogen production from chemical wastewater treatment in anaerobic sequencing batch biofilmreactor (AnSBBR) by bioaugmenting with selectively enriched kanamycin resistant anaerobic mixed consortia. Int. J. Hydrogen Energy 32, 3284-3292.

116. Vignais, P.M., Magnin, J.-P., Willison, J.C., 2006. Increasing biohydrogen production by metabolic engineering. Int. J. Hydrogen Energy 31, 1478-1483.

117. Valdez-Vazquez, I., Ríos-Leal, E., Muñoz-Páez, K.M., Carmona-Martínez, A., Poggi-Varaldo, H.M., 2006. Effect of inhibition treatment, type of inocula and 
incubation temperature on batch $\mathrm{H}_{2}$ production from organic solid waste. Biotechnol. Bioeng., 95, 342-349.

118. Wang, A., Ren, N., Shi, Y., Lee, D.J., 2008. .Bioaugmented hydrogen production from microcrystalline cellulose using co-culture-Clostridium acetobutylicum X9 and Ethanoigenens harbinense B49. Int. J. Hydrogen Energy 33, 912-917.

119. Weemaes, M.P.J., Verstraete, W.H., 1998. Evaluation of current wet sludge disintegration techniques. J. Chem. Technol. Biotechnol. 73, 83-92.

120. Whang, L.M., Hsiao, C.J., Cheng, S.S., 2006. A dual-substrate steady-state model for biological hydrogen production in an anaerobic hydrogen fermentation process. Biotechnol. Bioeng., 95, 492-500.

121. Wu, S.Y., Lin, C.N., Chang, J.S., Lee, K.S., Lin, P.J., 2002. Microbial hydrogen production with immobilized sewage sludge. Biotechnol. Prog. 18, 921-926.

122. Wu, J-H., Lin, C-Y., 2004. Biohydrogen production by mesophilic fermentation of food wastewater. Water Sci. Technol. 49, 223-228.

123. Xiao, B.Y., Liu, J.X., 2009. Effects of various pretreatments on biohydrogen production from sewage sludge. Chinese Sci. Bull. 54, 2038-2044.

124. Xing, D., Ren, N., Rittmann, B.E., 2008. Genetic diversity of hydrogenproducing bacteria in an acidophilic ethanol- $\mathrm{H}_{2}$-coproducing system, analyzed using the [Fe]-hydrogenase gene. Appl. Environ. Microbiol. 74, 1232-1239.

125. Yang, H., Guo, L., Liu, F., 2010. Enhanced bio-hydrogen production from corncob by a two-step process: Dark- and photo-fermentation. Bioresource Technol. 101, 2049-2052.

126. Yokoi, H., Saitsu, A., Uchida, H., Hirose, J., Hayashi, S., Takasaki, Y. 2001. Microbial hydrogen production from sweet potato starch residue. J. Biosci. Bioeng. 91, 58-63.

127. Yoshida, A., Nishimura, T., Kawaguchi, H., Inui, M., Yukawa, H., 2005. Enhanced hydrogen production from formic acid by formate hydrogenlyase overexpressing Escherichia coli strain. Appl. Environ. Microbiol. 71, 67626768.

128. Yoshino, F., Ikeda, H., Masukawa, H., Sakurai, H., 2007. High photobiological hydrogen production activity of a Nostoc sp. PCC 7422 uptake hydrogenaseDeficient mutant with high nitrogenase activity. Mar. Biotechnol. 9, 101-112.

129. $\mathrm{Yu}, \mathrm{H} . \mathrm{Q} ., \mathrm{Mu}, \mathrm{Y} ., 2$ 2006. Biological hydrogen production in a UASB reactor with granules. II: Reactor performance in 3-year operation. Biotechnol. Bioeng., 94, 988-995.

130. Zhang, Z.-P., Show, K.-Y., Tay, J.-H., Liang, D.T., Lee, D.-J., 2008 a. Biohydrogen production with anaerobic fluidized bed reactors-A comparison of biofilm-based and granule-based systems. Int. J. Hydrogen Energy 33, 1559-1564.

131. Zhang, Z.-P., Show, K.-Y., Tay, J.-H., Liang, D.T., Lee, D.-J., 2008b. Enhanced continuous biohydrogen production by immobilized anaerobic microflora. Energy \& Fuels 22, 87-92.

132. Zhang, M.-L., Fan, Y.-T., Xing, Y., Pan, C.-M., Zhang, G.-S., Lay, J.-J., 2007a. Enhanced biohydrogen production from cornstalk wastes with acidification pretreatment by mixed anaerobic cultures. Biomass Bioenergy 31, 250-254.

133. Zhang, Z.-P., Tay, J.-H., Show, K.-Y., Yan, R., Liang, D.T., Lee, D.-J., Jiang, W.-J., 2007b. Biohydrogen production in a granular activated carbon anaerobic fluidized bed reactor. Int. J. Hydrogen Energy 32, 185-191. 
134. Zhang, C., Xing, X.H., Lou, K., 2005. Rapid detection of a gfp-marked Enterobacter aerogenes under anaerobic conditions by aerobic fluorescence recovery. FEMS Microbiol. Lett. 249, 211-281.

135. Zhao, B-H., Yue, Z-B., Zhao, Q-B., Mu, Y., Yu, H-Q., Harada, H., Li, Y-Y., 2008. Optimization of hydrogen production in a granule-based UASB reactor. Int. J. Hydrogen Energy, 33, 2454-2461.

136. Zheng, G., Kang, Z., Qian, Y., Wang. L., 2009. Enhanced biohydrogen generation from organic wastewater containing $\mathrm{NH}_{4}{ }^{+}$by phototrophic bacteria Rhodobacter sphaeroides AR-3. Frontiers Environ. Sci. Eng. China 3, 387392.

137. Zhu, H., Béland, M., 2006. Evaluation of alternative methods of preparing hydrogen producing seeds from digested wastewater sludge. Int. J. Hydrogen Energy 31, 1980-1988.

138. Domènech, X., Ayllón, J.A., Peral, J., Rieradevall, J., 2002. How Green Is a Chemical Reaction? Application of LCA to Green Chemistry. Environ. Sci. Technol. 36, 5517-5520.

139. Akutsu, Y., Li, Y-Y, Harada, H., Yu, H-Q., 2009. Effects of temperature and substrate concentration on biological hydrogen production from starch. Int. J. Hydrogen Energy 34, 2558-2566.

140. Chen, W-H., Sung, S., Chen, S-Y., 2009. Biological hydrogen production in an anaerobic sequencing batch reactor: $\mathrm{pH}$ and cyclic duration effects. Int. J. Hydrogen Energy 34, 227-234. 